\title{
Non-OH chemistry in oxidation flow reactors for the study of atmospheric chemistry systematically examined by modeling
}

\author{
Zhe Peng ${ }^{1,2}$, Douglas A. Day ${ }^{1,2}$, Amber M. Ortega ${ }^{1,3, a}$, Brett B. Palm ${ }^{1,2}$, Weiwei Hu ${ }^{1,2}$, Harald Stark ${ }^{1,2,5}$, Rui Li ${ }^{1,3,4, b}$, \\ Kostas Tsigaridis $^{6}$, William H. Brune ${ }^{7}$, and Jose L. Jimenez ${ }^{1,2}$ \\ ${ }^{1}$ Cooperative Institute for Research in Environmental Sciences, University of Colorado, Boulder, CO 80309, USA \\ ${ }^{2}$ Department of Chemistry and Biochemistry, University of Colorado, Boulder, CO 80309, USA \\ ${ }^{3}$ Department of Atmospheric and Oceanic Sciences, University of Colorado, Boulder, CO 80309, USA \\ ${ }^{4}$ Chemical Sciences Division, Earth System Research Laboratory, National Oceanic and Atmospheric \\ Administration, Boulder, CO 80305, USA \\ ${ }^{5}$ Aerodyne Research, Inc., Billerica, MA 01821, USA \\ ${ }^{6}$ Center for Climate Systems Research, Columbia University, and NASA Goddard Institute for Space Studies, \\ New York, NY 10025, USA \\ ${ }^{7}$ Department of Meteorology, Pennsylvania State University, University Park, PA 16802, USA \\ ${ }^{a}$ now at: Chemical and Environmental Engineering, University of Arizona, Tucson, AZ 85721, USA \\ ${ }^{b}$ now at: Markes International, Inc., Cincinnati, OH 45242, USA
}

Correspondence to: Jose L. Jimenez (jose.jimenez@colorado.edu)

Received: 30 July 2015 - Published in Atmos. Chem. Phys. Discuss.: 1 September 2015

Revised: 14 March 2016 - Accepted: 15 March 2016 - Published: 6 April 2016

\begin{abstract}
Oxidation flow reactors (OFRs) using lowpressure $\mathrm{Hg}$ lamp emission at 185 and $254 \mathrm{~nm}$ produce $\mathrm{OH}$ radicals efficiently and are widely used in atmospheric chemistry and other fields. However, knowledge of detailed OFR chemistry is limited, allowing speculation in the literature about whether some non-OH reactants, including several not relevant for tropospheric chemistry, may play an important role in these OFRs. These non-OH reactants are UV radiation, $\mathrm{O}\left({ }^{1} \mathrm{D}\right), \mathrm{O}\left({ }^{3} \mathrm{P}\right)$, and $\mathrm{O}_{3}$. In this study, we investigate the relative importance of other reactants to $\mathrm{OH}$ for the fate of reactant species in OFR under a wide range of conditions via box modeling. The relative importance of non-OH species is less sensitive to UV light intensity than to water vapor mixing ratio $\left(\mathrm{H}_{2} \mathrm{O}\right)$ and external $\mathrm{OH}$ reactivity $\left(\mathrm{OHR}_{\text {ext }}\right)$, as both non- $\mathrm{OH}$ reactants and $\mathrm{OH}$ scale roughly proportionally to UV intensity. We show that for field studies in forested regions and also the urban area of Los Angeles, reactants of atmospheric interest are predominantly consumed by $\mathrm{OH}$. We find that $\mathrm{O}\left({ }^{1} \mathrm{D}\right), \mathrm{O}\left({ }^{3} \mathrm{P}\right)$, and $\mathrm{O}_{3}$ have relative contributions to volatile organic compound (VOC) consumption that are similar or lower than in the troposphere. The impact of $\mathrm{O}$ atoms can be neglected under most conditions in both OFR and
\end{abstract}

troposphere. We define "riskier OFR conditions" as those with either low $\mathrm{H}_{2} \mathrm{O}(<0.1 \%)$ or high $\mathrm{OHR}_{\text {ext }}\left(\geq 100 \mathrm{~s}^{-1}\right.$ in OFR185 and $>200 \mathrm{~s}^{-1}$ in OFR254). We strongly suggest avoiding such conditions as the importance of non-OH reactants can be substantial for the most sensitive species, although $\mathrm{OH}$ may still dominate under some riskier conditions, depending on the species present. Photolysis at nontropospheric wavelengths (185 and $254 \mathrm{~nm}$ ) may play a significant (> 20\%) role in the degradation of some aromatics, as well as some oxidation intermediates, under riskier reactor conditions, if the quantum yields are high. Under riskier conditions, some biogenics can have substantial destructions by $\mathrm{O}_{3}$, similarly to the troposphere. Working under low $\mathrm{O}_{2}$ (volume mixing ratio of 0.002 ) with the OFR 185 mode allows $\mathrm{OH}$ to completely dominate over $\mathrm{O}_{3}$ reactions even for the biogenic species most reactive with $\mathrm{O}_{3}$. Non-tropospheric VOC photolysis may have been a problem in some laboratory and source studies, but can be avoided or lessened in future studies by diluting source emissions and working at lower precursor concentrations in laboratory studies and by humidification. Photolysis of secondary organic aerosol (SOA) samples is estimated to be significant (>20\%) under 
the upper limit assumption of unity quantum yield at medium $\left(1 \times 10^{13}\right.$ and $1.5 \times 10^{15}$ photons $\mathrm{cm}^{-2} \mathrm{~s}^{-1}$ at 185 and $254 \mathrm{~nm}$, respectively) or higher UV flux settings. The need for quantum yield measurements of both VOC and SOA photolysis is highlighted in this study. The results of this study allow improved OFR operation and experimental design and also inform the design of future reactors.

\section{Introduction}

For decades, environmental chambers have been employed to study atmospheric chemical processes, particularly volatile organic compound (VOC) oxidation processes in the atmosphere (Cocker et al., 2001; Carter et al., 2005; Presto et al., 2005; Wang et al., 2011; Platt et al., 2013), without the interference of some transport processes (e.g., advection and wet deposition). These oxidation processes are the key to secondary organic aerosol (SOA) formation (Odum et al., 1996; Hoffmann et al., 1997; Hallquist et al., 2009) and air pollutant removal (Levy, 1971). Atmospheric simulation chambers usually have volumes on the order of several $\mathrm{m}^{3}$ and use light sources longer than $300 \mathrm{~nm}$ (e.g., sunlight or UV black lights) to generate oxidants (mainly $\mathrm{OH}$ ). These settings leads to $\mathrm{OH}$ concentrations $\left(10^{6}-10^{8}\right.$ molecules $\left.\mathrm{cm}^{-3}\right)$ that are not much higher than the typical ambient values $\left(10^{6}-10^{7}\right.$ molecules $\mathrm{cm}^{-3}$; Mao et al., 2009). Relatively low $\mathrm{OH}$ concentrations require long residence/simulation times (generally hours) and limit the ability of those setups to reach very high photochemical ages that are atmospherically relevant (George et al., 2007; Kang et al., 2007; Carlton et al., 2009; Seakins, 2010; Wang et al., 2011). Residence times are ultimately limited due to losses of gases and particles to Teflon walls with timescales of tens of minutes to several hours (Cocker et al., 2001; Matsunaga and Ziemann, 2010; Zhang et al., 2014) as well as by the limited volume of the bag relative to the sampling instrumentation (Nguyen et al., 2014). Besides, large sizes and support systems (e.g., clean air generators) make it difficult to use large chambers in field or source studies.

Oxidation flow reactors (OFRs) are an alternative that offers some advantages over environmental chambers, especially for rapid changes of experimental conditions and/or for field experiments. They generally have a smaller size (on the order of $10 \mathrm{~L}$ ) and typically use low-pressure $\mathrm{Hg}$ lamps as light sources for producing $\mathrm{OH}$ in large amounts via $\mathrm{O}_{3}$ and/or $\mathrm{H}_{2} \mathrm{O}$ photolysis. These design choices lead to good portability, short experimental timescales, ability to reach long photochemical ages, and potentially reduced wall losses.

Due to these advantages, OFRs have been employed in many recent field and laboratory studies in atmospheric chemistry, particularly in SOA-related research (George et al., 2007; Kang et al., 2007, 2011; Smith et al., 2009; Mas- soli et al., 2010; Cubison et al., 2011; Lambe et al., 2011a, b, 2012, 2013; Bahreini et al., 2012; Saukko et al., 2012; Wang et al., 2012; Ortega et al., 2013; Li et al., 2013). OFRs are also used in related applied fields, such as scrubbing of pollution from air (Johnson et al., 2014). In contrast to their popularity, the chemistry occurring in OFRs is still incompletely characterized, although the formation and interconversion reactions of most oxidants in OFRs have been well characterized (Sander et al., 2011; Ammann et al., 2015). To our knowledge, there are only three studies of OFR radical oxidation chemistry to date. Ono et al. (2014) focused on the dependence of $\mathrm{O}_{3}$ destruction on $\mathrm{H}_{2} \mathrm{O}$ concentration. We have recently made progress on the characterization of $\mathrm{HO}_{x}$ radical chemistry in OFRs (Li et al., 2015; Peng et al., 2015). We have developed a kinetic model for OFRs, which provides predictions in good agreement with laboratory experiments. This model has also shown that $\mathrm{OH}$ exposure $\left(\mathrm{OH}_{\text {exp }}\right.$, i.e., $\mathrm{OH}$ concentration integrated over the reactor residence time) increases with $\mathrm{H}_{2} \mathrm{O}$ concentration and UV intensity, and decreases with external $\mathrm{OH}$ reactivity $\left(\mathrm{OHR}_{\mathrm{ext}}=\sum k_{i} c_{i}\right.$, i.e., the sum of the products of concentrations of externally introduced $\mathrm{OH}$-consuming species $\left(c_{i}\right)$ and rate constants of their reactions with $\left.\mathrm{OH}\left(k_{i}\right)\right)$. The $\mathrm{OH}_{\text {exp }}$ decrease due to $\mathrm{OHR}_{\text {ext }}$ was defined as "OH suppression" and can reach 2 orders of magnitude in some cases (Li et al., 2015; Peng et al., 2015). We also showed that relative uncertainties of the outputs of our box model (e.g., $\mathrm{OH}_{\mathrm{exp}}$ ) due to uncertain kinetic parameters are typically only $20 \%$ (Peng et al., 2015). However, none of these studies directly address the fate of VOCs (including oxygenated VOCs), simply regarded as external $\mathrm{OH}$ reactants in the prior studies.

The primary reason for the use of the OFRs studied here is for the study of reactions of species or mixtures of atmospheric relevance with the $\mathrm{OH}$ radical. However, other highly reactive species are also present at very elevated concentrations, including the radicals $\mathrm{O}\left({ }^{1} \mathrm{D}\right)$ and $\mathrm{O}\left({ }^{3} \mathrm{P}\right), 185$ and $254 \mathrm{~nm}$ photons, and $\mathrm{O}_{3}$. If a substantial fraction of the species of interest reacted with those non-OH reactants, then the chemistry in the OFR would deviate from the $\mathrm{OH}$ radical chemistry intended to investigate. The absence of systematic research on VOC fate in OFRs leaves room for some speculation that non-OH or non-tropospheric chemistry can play a major role in OFRs; for example, Johnson et al. (2014) suggested that $\mathrm{O}\left({ }^{1} \mathrm{D}\right)$ and $\mathrm{O}\left({ }^{3} \mathrm{P}\right)$ significantly consumed VOCs. Klems et al. (2015) concluded that photons at $254 \mathrm{~nm}$ from Hg-lamp emission played an important role in their OFR experiment, especially for downstream chemistry. Lack of clarity about these types of questions and of clear guidelines about how to apply OFRs to avoid such problems have limited the application of OFRs for years. In this paper, we apply the model in Peng et al. (2015) to systematically investigate whether significant non-tropospheric or non-OH chemistry occurs in OFRs and what experimental conditions make it more important. Considering the enormous complexity of organic radical (particularly organic peroxy) chemistry, we 
only examine the non-OH fate of stable species in the present work. The fate of organic radicals should be the subject of future studies. The results allow improved OFR operation and experimental design, as well as guidance for the design of future reactors.

\section{Methods}

The OFR and the model used here have been described in detail elsewhere (Kang et al., 2007; Li et al., 2015; Peng et al., 2015). Here, we only present a brief introduction for each.

\subsection{Potential Aerosol Mass (PAM) flow reactor}

Kang et al. (2007) first introduced the PAM flow reactor. Although there were earlier versions of the PAM reactor, the version of cylindrical geometry with a volume of $\sim 13 \mathrm{~L}$ has been widely used and is currently in use in many SOA research groups (Massoli et al., 2010; Cubison et al., 2011; Kang et al., 2011; Lambe et al., 2011a, b, 2012, 2013; Bahreini et al., 2012; Saukko et al., 2012; Wang et al., 2012; Li et al., 2013; Ortega et al., 2013). The reactor is made of aluminum or of glass and aluminum and equipped with 1-4 low-pressure Hg lamps (model no. 82-9304-03, BHK Inc.) located inside the flow tube. The $\mathrm{Hg}$ lamps produce UV emissions at 185 and $254 \mathrm{~nm}$, the intensity of which can be rapidly computer-controlled. The operation mode using both 185 and $254 \mathrm{~nm}$ emissions is called "OFR185". In this mode, photons at $185 \mathrm{~nm}$ dissociate $\mathrm{H}_{2} \mathrm{O}$ and $\mathrm{O}_{2}$ molecules to produce $\mathrm{OH}+\mathrm{H}$ and $\mathrm{O}\left({ }^{3} \mathrm{P}\right)$, respectively. Recombination of $\mathrm{O}\left({ }^{3} \mathrm{P}\right)$ with $\mathrm{O}_{2}$ forms $\mathrm{O}_{3}$. UV light at $254 \mathrm{~nm}$ then photolyzes $\mathrm{O}_{3}$ to produce $\mathrm{O}\left({ }^{1} \mathrm{D}\right)$, which reacts with $\mathrm{H}_{2} \mathrm{O}$ and produces additional $\mathrm{OH}$. OFR can also be operated in another mode where photons at $185 \mathrm{~nm}$ are filtered by quartz sleeves around the lamps. In this case, only $254 \mathrm{~nm}$ UV light is active to generate $\mathrm{OH}$ ("OFR254" mode), and injection of externally generated $\mathrm{O}_{3}$ into the reactor is required for $\mathrm{OH}$ production. The amount of injected $\mathrm{O}_{3}$ plays a critical role in the OFR chemistry (Peng et al., 2015). For this reason this amount $(X \mathrm{ppm})$ is also included in OFR operation mode notation in the form of OFR254- $X$. For example, OFR254-70 and OFR254-7 denote experiments with 70 and $7 \mathrm{ppm} \mathrm{O}_{3}$ injected, respectively. We use the PAM as the basic OFR design. Other designs will be specified below if needed. Rapid computer-controlled UV lamp setting allows rapidly scanning UV lamp settings during an experiment and has unique applications to OFR experiments in field studies (Hu et al., 2015; Ortega et al., 2015; Palm et al., 2016). In these experiments, OFRs enable the exploration of a very large range of photochemical age during a short period $(\sim 2 \mathrm{~h})$ when ambient conditions often do not significantly change.

\subsection{Model description}

We use the same model as in Peng et al. (2015), a standard chemical-kinetic model under plug-flow conditions. The effect of non-plug-flow residence time distributions (RTDs) was also investigated in that study. Non-plug-flow models result in similar $\mathrm{OH}_{\text {exp }}$ than plug flow in most cases, except under specific conditions with very high $\mathrm{UV}, \mathrm{H}_{2} \mathrm{O}$, and $\mathrm{OHR}_{\text {ext }}$ (Peng et al., 2015). Therefore, plug-flow $\mathrm{OH}_{\text {exp }}$ is used in this study, as a proxy of $\mathrm{OH}_{\text {exp }}$ estimated from $\mathrm{OHR}_{\text {ext }}$ decay and to avoid the much increased computational expense for complex RTDs. All $\mathrm{O}_{x}$ and $\mathrm{HO}_{x}$ reactions available in the JPL Chemical Kinetic Data Evaluation (Sander et al., 2011) are taken into account. Reactions of some external $\mathrm{OH}$ reactants (externally introduced reactants destructing $\mathrm{OH}$ ), such as $\mathrm{SO}_{2}, \mathrm{CO}$, and $\mathrm{NO}_{x}$, are also included. $\mathrm{SO}_{2}$ is used as a proxy of other external $\mathrm{OH}$ reactants (e.g., VOCs). We believe that this is a realistic approximation in terms of $\mathrm{OHR}_{\mathrm{ext}}$ decay vs. $\mathrm{OH}_{\text {exp }}$ for many precursors, as discussed in Peng et al. (2015).

When studying the OFR, we assume a residence time of $180 \mathrm{~s}$ and use typical temperature $(295 \mathrm{~K})$ and atmospheric pressure ( 835 mbar) in Boulder, $\mathrm{CO}$, USA. $\mathrm{H}_{2} \mathrm{O}$ mixing ratio (abbr. $\mathrm{H}_{2} \mathrm{O}$ hereafter) ranges from 0.07 to $2.3 \%$ (equivalent to relative humidity, $\mathrm{RH}$, of $2-71 \%$ ). According to $\mathrm{Li}$ et al. (2015), UV photon fluxes (abbr. UV hereafter) at 185 and $254 \mathrm{~nm}$ are estimated to be in the ranges $1.0 \times 10^{11}$ $1.0 \times 10^{14}$ and $4.2 \times 10^{13}-8.5 \times 10^{15}$ photons $\mathrm{cm}^{-2} \mathrm{~s}^{-1}$, respectively. $\mathrm{OHR}_{\mathrm{ext}}$ at 0 and between 1 and $1000 \mathrm{~s}^{-1}$, covering the range of most field and laboratory studies, are investigated. In the explored parameter space, the same threecharacter labels as in Peng et al. (2015) are used to denote typical cases (Table 1). For OFR254, we study OFR254-7 to -70, representing OFR254 experiments with low (Kang et al., 2011; Liu et al., 2015) and high $\mathrm{O}_{3}$ (Palm et al., 2016), respectively. To model literature OFR studies, we adopt corresponding parameters (reactor volume, $\mathrm{H}_{2} \mathrm{O}$, residence time, etc.), and estimate parameters that are specified or measured (e.g., UV) as needed. In particular, for some field studies, where long time-series of experimental data (42 days in BEACHON-RoMBAS (Palm et al., 2016), 42 days in SOAS (Hu et al., 2015), and 15 days in CalNex-LA (Ortega et al., 2015)) were recorded, we model all valid data points and present outputs in the form of histograms. Note that the outputs for field studies, i.e., histograms, have a complex dependence on ambient temperature, $\mathrm{H}_{2} \mathrm{O}$, and $\mathrm{OHR}_{\text {ext }}$, as well as UV steps used. The specific histogram shapes for different field campaigns are influenced by both ambient and experimental parameters.

\section{Results and discussions}

In the following sections we explore the relative importance of five non-OH pathways (photons at 185 and $254 \mathrm{~nm}$, 
Table 1. Code of the labels of typical cases. A case label is composed of three characters denoting the water mixing ratio, the photon flux, and the external $\mathrm{OH}$ reactivity, respectively.

\begin{tabular}{|c|c|c|c|}
\hline & Water mixing ratio & Photon flux & External OH reactivity \\
\hline \multirow{4}{*}{ Options } & $\begin{array}{l}\mathrm{L} \text { is low } \\
(0.07 \%)\end{array}$ & $\begin{array}{l}\mathrm{L} \text { is low }\left(10^{11} \text { photons } \mathrm{cm}^{-2} \mathrm{~s}^{-1} \text { at } 185 \mathrm{~nm} \text {; }\right. \\
\left.4.17 \times 10^{13} \text { photons } \mathrm{cm}^{-2} \mathrm{~s}^{-1} \text { at } 254 \mathrm{~nm}\right)\end{array}$ & 0 \\
\hline & $\begin{array}{l}\mathrm{M} \text { is medium } \\
(1 \%)\end{array}$ & $\begin{array}{l}\mathrm{M} \text { is medium }\left(10^{13} \text { photons } \mathrm{cm}^{-2} \mathrm{~s}^{-1} \text { at } 185 \mathrm{~nm}\right. \\
\left.1.45 \times 10^{15} \text { photons } \mathrm{cm}^{-2} \mathrm{~s}^{-1} \text { at } 254 \mathrm{~nm}\right)\end{array}$ & $\begin{array}{l}\mathrm{L} \text { is low }\left(10 \mathrm{~s}^{-1}\right) \\
\text { typically for remote or clean urban air }\end{array}$ \\
\hline & $\begin{array}{l}\mathrm{H} \text { is high } \\
(2.3 \%)\end{array}$ & $\begin{array}{l}\mathrm{H} \text { is high }\left(10^{14} \text { photons } \mathrm{cm}^{-2} \mathrm{~s}^{-1} \text { at } 185 \mathrm{~nm}\right. \\
\left.8.51 \times 10^{15} \text { photons } \mathrm{cm}^{-2} \mathrm{~s}^{-1} \text { at } 254 \mathrm{~nm}\right)\end{array}$ & $\begin{array}{l}\mathrm{H} \text { is high }\left(100 \mathrm{~s}^{-1}\right) \\
\text { typically for polluted urban air }\end{array}$ \\
\hline & & $\begin{array}{l}\text { "L" is lowest in PAM by Li et al. }(2015) \\
\left(7.9 \times 10^{11} \text { photons } \mathrm{cm}^{-2} \mathrm{~s}^{-1} \text { at } 185 \mathrm{~nm} \text {; }\right. \\
\left.2.04 \times 10^{14} \text { photons } \mathrm{cm}^{-2} \mathrm{~s}^{-1} \text { at } 254 \mathrm{~nm}\right)\end{array}$ & $\begin{array}{l}\mathrm{V} \text { is very high }\left(1000 \mathrm{~s}^{-1}\right) \\
\text { only for laboratory experiments }\end{array}$ \\
\hline Example & LHO: & low water mixing ratio, high photon flux, no extern & OH reactivity \\
\hline
\end{tabular}

$\mathrm{O}\left({ }^{1} \mathrm{D}\right), \mathrm{O}\left({ }^{3} \mathrm{P}\right)$, and $\left.\mathrm{O}_{3}\right)$ vs. the $\mathrm{OH}$ reaction for species of atmospheric interest, including a variety of typical biogenic and anthropogenic VOCs and a few important inorganic species (e.g., $\mathrm{SO}_{2}$ and $\mathrm{NO}_{2}$ ). Because of the huge complexity of VOC oxidation mechanisms, only consumption/oxidation of specific VOCs is investigated. In such an investigation, a large amount of kinetic data is required. We collected the required data (Tables S1-S3 in the Supplement) according to the principles in Sect. S1. Photolysis of SOA is also investigated.

\subsection{Fractional loss of VOCs to non-OH reactants}

As shown in Peng et al. (2015), $\mathrm{OH}_{\exp }$ in OFRs depends on various physical conditions, e.g., $\mathrm{H}_{2} \mathrm{O}$ and $\mathrm{OHR}_{\text {ext }}$. However, the non-OH reactants are much less dependent on these parameters. $\mathrm{H}_{2} \mathrm{O}$ and external $\mathrm{OH}$ reactants only contribute less than $1 \%$ to absorption at 185 and $254 \mathrm{~nm}$. Therefore, they have almost no impact on effective $\mathrm{UV} . \mathrm{O}_{3}$ can absorb a fraction of the $254 \mathrm{~nm}$ radiation, but the optical depth due to $70 \mathrm{ppm} \mathrm{O}_{3}$ in the reactor is $\sim 0.11$, and thus the attenuation of $254 \mathrm{~nm}$ photons by $\mathrm{O}_{3}$ absorption is a minor effect. The dominant fates of $\mathrm{O}\left({ }^{1} \mathrm{D}\right)$ and $\mathrm{O}\left({ }^{3} \mathrm{P}\right)$ are the quenching by air and the recombination with $\mathrm{O}_{2}$, respectively, with which no reactions involving $\mathrm{H}_{2} \mathrm{O}$ or external $\mathrm{OH}$ reactants can compete. Thus the concentrations of $\mathrm{O}\left({ }^{1} \mathrm{D}\right)$ and $\mathrm{O}\left({ }^{3} \mathrm{P}\right)$ in the reactor depend on UV intensity and $\mathrm{H}_{2} \mathrm{O}$, but not on OHR $\mathrm{Oxt}_{\text {. }}$. Since $\mathrm{OH}$ can be strongly modulated by $\mathrm{OHR}_{\text {ext }}$, changing input conditions may result in very different relative importance of $\mathrm{OH}$ to other reactive species. To fully evaluate this issue, it is necessary to explore a very wide range of conditions as in Peng et al. (2015).

\subsubsection{Common features of all the non-OH reactants}

Figures 1-5 show the relative consumption of several species vs. ratio of exposures to individual non-OH species (X) to
$\mathrm{OH}$ exposure $\left(\mathrm{X}_{\mathrm{exp}} / \mathrm{OH}_{\mathrm{exp}}\right)$ for 185 and $254 \mathrm{~nm}$ photons, $\mathrm{O}\left({ }^{1} \mathrm{D}\right), \mathrm{O}\left({ }^{3} \mathrm{P}\right)$, and $\mathrm{O}_{3}$, respectively. Figures $\mathrm{S} 1-\mathrm{S} 5$ present the same information in an alternative format that may be useful to evaluate the fate of species not included in our study. They show ratios of rate constants of species with $\mathrm{OH}$ to those with non- $\mathrm{OH}$ species $(\mathrm{X})$, mathematically equivalent to the $\mathrm{X}_{\exp } / \mathrm{OH}_{\exp }$ where corresponding $\mathrm{X} /(\mathrm{OH}+\mathrm{X})$ is $50 \% . \mathrm{X} /(\mathrm{OH}+\mathrm{X})$ denotes the fractional importance of $\mathrm{X}$ in the sum of the contribution of $\mathrm{OH}$ and $\mathrm{X}$ to VOC. If a $\mathrm{VOC}$ has a higher ratio of rate constant with $\mathrm{OH}$ to that with a non-OH reactant $(\mathrm{X})$ than with another reactant $(\mathrm{Y})$, the relative contribution of $\mathrm{X}, \mathrm{X} /(\mathrm{OH}+\mathrm{X})$, should be smaller than that of $\mathrm{Y}$. In these figures, we also show the $\mathrm{X}_{\exp } / \mathrm{OH}_{\exp }$ fractional occurrence distribution for OFR254 and OFR185, under different conditions, including key laboratory and field studies, and identify the $\mathrm{X}_{\exp } / \mathrm{OH}_{\exp }$ ranges where non-OH contribution to species fate is significant. Unless specifically stated, a dissociation quantum yield of unity is assumed for the photolysis reactions, which results in upper limits for the relative importance of those pathways.

In these figures, the relationships of all non-OH reactive species to $\mathrm{OH}$ are similar for certain common conditions. We define three types of conditions to help guide experimental design and evaluation in terms of the relative importance of non-OH reactants. Under "riskier conditions" of high/very high OHR ext $\left(\geq 100 \mathrm{~s}^{-1}\right.$ in OFR185 and $>200 \mathrm{~s}^{-1}$ in OFR254-7 to -70$)$ and/or low $\mathrm{H}_{2} \mathrm{O}(<0.1 \%)$, non-OH reactions can be significant depending on the species. Conversely, under "safer conditions" with relatively low $\mathrm{OHR}_{\mathrm{ext}}$ $\left(<30 \mathrm{~s}^{-1}\right.$ in OFR 185 and $<50 \mathrm{~s}^{-1}$ in OFR254) and high $\mathrm{H}_{2} \mathrm{O}$ ( $>0.8 \%$ in OFR 185 and $>0.5 \%$ in OFR254), and moderate or higher $\mathrm{UV}\left(>1 \times 10^{12}\right.$ photons $\mathrm{cm}^{-2} \mathrm{~s}^{-1}$ at $\left.185 \mathrm{~nm}\right)$ in OFR185, reaction with OH is dominant (Figs. 1-5 and S1$5)$. We denote all other conditions as "transition conditions". High $\mathrm{H}_{2} \mathrm{O}$ and zero/low $\mathrm{OHR}_{\text {ext }}$ lead to strong $\mathrm{OH}$ production and no/weak $\mathrm{OH}$ suppression, respectively. Thus, $\mathrm{OH}$ 


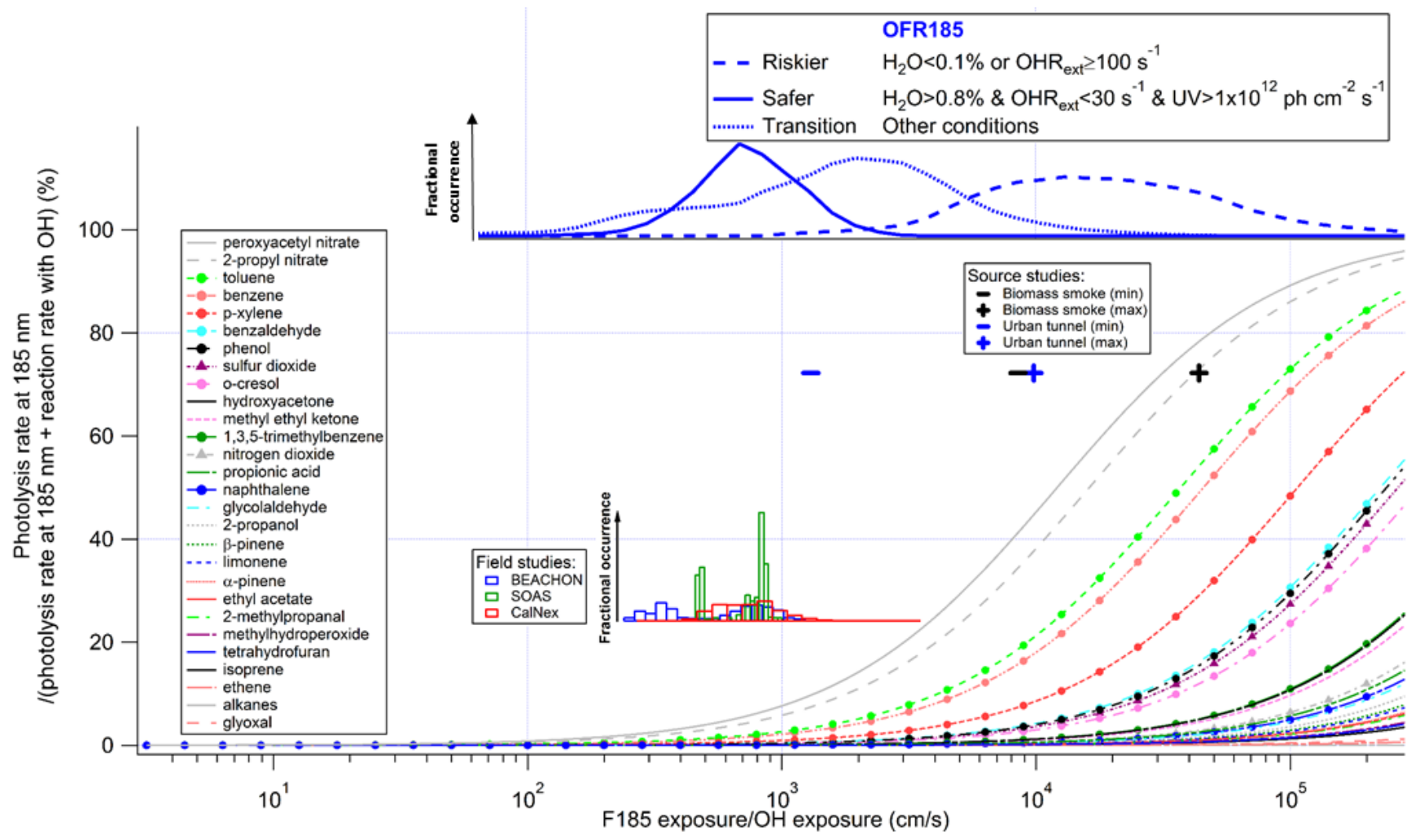

Figure 1. Fractional importance of the photolysis rate at $185 \mathrm{~nm}$ of several species of interest vs. the reaction rate with $\mathrm{OH}$, as a function of the ratio of exposure to $185 \mathrm{~nm}$ photons (F185) and $\mathrm{OH}$. F185 exposure (in photons $\mathrm{cm}^{-2}$ ) is the product of $185 \mathrm{~nm}$ photon flux (in photons $\mathrm{cm}^{-2} \mathrm{~s}^{-1}$ ) and time (in s). F185 exposure $/ \mathrm{OH}$ exposure is thus in $\mathrm{cm} \mathrm{s}^{-1}$. The modeled frequency distributions of ratios of $185 \mathrm{~nm}$ photon exposure to $\mathrm{OH}$ exposure under riskier, safer, and transition conditions for OFR185 are also shown. The curves of aromatics and inorganic gases are highlighted by solid dots and upward triangles, respectively. The lower inset shows histograms of model-estimated F185 / OH exposures for three field studies where OFR185 was used to process ambient air. Their ordinate is the fractional occurrence of a given condition $\left(\mathrm{X}_{\mathrm{exp}} / \mathrm{OH}_{\mathrm{exp}}\right.$ ). All histograms are normalized to be of identical total area (i.e., total probability of 1). The upper inset (black and blue markers) shows similar information for source studies of biomass smoke (FLAME-3; Ortega et al., 2013) and an urban tunnel (Tkacik et al., 2014). All curves, markers, and histograms in this figure share the same abscissa.

is more abundant and dominates species consumption under those conditions. In the case of low $\mathrm{H}_{2} \mathrm{O}$ and high $\mathrm{OHR}_{\text {ext }}$, $\mathrm{OH}$ is generally lower because of less production and more suppression. These conditions increase the relative contribution of non-OH species. UV light intensity is generally less influential on non-OH VOC fate than $\mathrm{H}_{2} \mathrm{O}$ and $\mathrm{OHR}_{\text {ext }}$, although $\mathrm{OH}$ production is nearly proportional to UV (Peng et al., 2015), because the non-OH reactive species also scale (nearly) proportional to UV. As a result, UV generally has smaller effects on exposure ratios between $\mathrm{OH}$ and the non$\mathrm{OH}$ reactants. However, under a UV near the lower bound of the explored range in this study $\left(<1 \times 10^{12}\right.$ photons $\mathrm{cm}^{-2} \mathrm{~s}^{-1}$ at $185 \mathrm{~nm}$ ) in OFR185, OH production is so small that the effect of $\mathrm{OHR}_{\text {ext }}$ on $\mathrm{OH}$ suppression can be amplified and hence some exposure ratios may be affected. In OFR254 $\mathrm{OH}$ is more resilient to suppression even at low UV because of the $\mathrm{OH}$ recycling by initially injected $\mathrm{O}_{3}$ (Peng et al., 2015). Note that we call these conditions "riskier" and "safer" mainly in terms of non-tropospheric VOC fate but not of VOC fate by all non-OH reactants, as some of the non$\mathrm{OH}$ reactant studied in this work may also play a role under some tropospheric conditions (see Sect. 3.1.4 and 3.1.5). In addition to the common features above, individual non- $\mathrm{OH}$ reactants have their own features as well as a few exceptions to the above mentioned general observations, which we will detail below.

\subsubsection{Reactions with $\mathrm{OH}$ vs. photolysis at $185 \mathrm{~nm}$}

Under riskier reactor conditions, photolysis at $185 \mathrm{~nm}$ of several aromatic compounds, such as toluene, benzene, and pxylene, are estimated to be significant and even dominant vs. the $\mathrm{OH}$ reactions (Fig. 1). This results from their aromatic ring, which is not only highly efficient as a chromophore but also relatively resistant to $\mathrm{OH}$ attack.

It is not common to perform field studies for $\mathrm{SOA}$ at $\mathrm{H}_{2} \mathrm{O}$ as low as $0.1 \%$ or $\mathrm{OHR}_{\text {ext }} \geq 100 \mathrm{~s}^{-1}$ (Table 1). According to $\mathrm{F} 185_{\exp } / \mathrm{OH}_{\exp }$ calculated from the field studies where 
OFR185 was deployed, i.e., BEACHON-RoMBAS (Palm et al., 2016), SOAS (Hu et al., 2015) and CalNex-LA (Ortega et al., 2015), all these studies are generally under safer conditions (infrequent low $\mathrm{H}_{2} \mathrm{O}$ mixing ratio and ambient $\mathrm{OH}$ reactivity estimated to be $\sim 15-25 \mathrm{~s}^{-1}$ ). For instance, none of these field studies fell into the conditions where the fractional importance of photolysis at $185 \mathrm{~nm}$ was significant for aromatic species. However, in some source studies using OFRs, e.g., when sampling biomass burning smoke (FLAME-3; Ortega et al., 2013) or air in a traffic tunnel (Tkacik et al.,

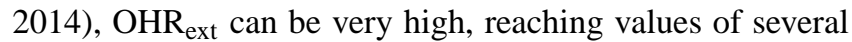
$100 \mathrm{~s}^{-1}$ (Table S4). Especially on the smoke study, photolysis of aromatics may have played a role. However, it has long been known that excited aromatic molecules may undergo various deactivation pathways (e.g., vibronic coupling, intersystem crossing, and collisional quenching) without molecular fragmentation (Beddard et al., 1974; Nakashima, 1982; Nakashima and Yoshihara, 1983; Fang and Phillips, 2002), preventing unity quantum yields. Therefore, the photolysis of aromatics at $185 \mathrm{~nm}$ in the above mentioned source studies may not be as significant as estimated in Fig. 1.

Under riskier conditions, some organic peroxy nitrates and nitrates (e.g., peroxyacetyl nitrate and 2-propyl nitrate in Fig. 1) have an estimated contribution from photolysis at $185 \mathrm{~nm}$ to their fate that is comparable to or even larger than that of reaction with $\mathrm{OH}$. Nevertheless, this does not mean that we need to make extra efforts to avoid the photolysis of organic nitrates and peroxy nitrates at $185 \mathrm{~nm}$. Although they have cross sections at $185 \mathrm{~nm} \sim 10-100$ times smaller than those of aromatics, these organic compounds react remarkably slowly with $\mathrm{OH}(\sim 2$ orders of magnitude slower than reactions of aromatics with $\mathrm{OH}$ ), so photolysis appears substantial with respect to reaction with $\mathrm{OH}$, but really two slow rates are being compared. Thus, absolute photolyzed amounts of these species are not substantial. For example, only $\sim 10 \%$ of peroxyacyl nitrate is photolyzed by $185 \mathrm{~nm}$ photons at the highest OFR185 lamp setting. Even if photolysis of nitrates and peroxy nitrates by low-pressure Hg lamp emission proceeds to a significant extent, it may still not be a problem, as it generally leads to the same products as their ambient photolysis (Renlund and Trott, 1984; Roberts and Fajer, 1989). Nitrate and peroxy nitrate photolysis is actually much more important in the atmosphere than in OFRs for the same photochemical age (see below and Fig. 6).

$\mathrm{SO}_{2}$ has been used in some studies to calibrate $\mathrm{OH}_{\exp }$ (Lambe et al., 2015; Li et al., 2015). It does undergo significant photolysis at $185 \mathrm{~nm}$ under riskier conditions. However, this photolysis does not lead to an overestimation of $\mathrm{OH}_{\text {exp }}$, since the S-bearing product of $\mathrm{SO}_{2}$ photolysis at $185 \mathrm{~nm}, \mathrm{SO}$, converts back to $\mathrm{SO}_{2}$ very rapidly through its reaction with $\mathrm{O}_{2}$.

Oxidation intermediates may also photolyze at $185 \mathrm{~nm}$. However, their photolysis is unlikely to be significant when OFR is operated under safer conditions. To clarify this issue, a detailed discussion about the photolysis of oxidation inter- mediates at $254 \mathrm{~nm}$ is required as a premise. We thus discuss oxidation intermediate photolysis at both 185 and $254 \mathrm{~nm}$ in Sect. 3.1.3.

\subsubsection{Reactions with $\mathrm{OH}$ vs. photolysis at $254 \mathrm{~nm}$}

The photon flux in the reactor at $254 \mathrm{~nm}$ is $80-250$ times larger than at $185 \mathrm{~nm}$ (Li et al., 2015). Although absorption cross sections of all molecules investigated in this study are significantly lower at 254 than $185 \mathrm{~nm}$, the higher photon flux compensates, at least partially, for this effect, so that in OFR185 photolysis of many species at $254 \mathrm{~nm}$ is of similar relative importance as photolysis at $185 \mathrm{~nm}$, with potentially important effects at low $\mathrm{H}_{2} \mathrm{O}$ and/or high $\mathrm{OHR}_{\text {ext }}$ (Figs. 2 and S2). As for $185 \mathrm{~nm}, 254 \mathrm{~nm}$ photolysis is a concern mainly for aromatic compounds, because of the high light absorptivity and low $\mathrm{OH}$ reactivity of aromatic rings as previously discussed. Again, note that this concern may be less serious than shown in Fig. 2 because of possible lower quantum yields. Photolysis of organic nitrates and peroxy nitrates at $254 \mathrm{~nm}$ also appears to be important relative to reactions with $\mathrm{OH}$ and is still not a concern for the same reasons as photolysis at $185 \mathrm{~nm} . \mathrm{SO}_{2}$ can absorb efficiently at $254 \mathrm{~nm}$, but it is still not a problem for $\mathrm{SO}_{2}$-based $\mathrm{OH}_{\text {exp }}$ calibration, since photons at $254 \mathrm{~nm}$ are not sufficiently energetic to dissociate $\mathrm{SO}_{2}$ molecules.

High UV generally appears to be more problematic than low UV in OFR254 (Fig. S2). This is in contrast to the trend of OFR185. In OFR254, $\mathrm{O}_{3}$ is the only primary $\mathrm{OH}$ source, and a substantial fraction of $\mathrm{O}_{3}$ can be photolyzed at the highest lamp settings, leading to a substantial reduction of $\mathrm{OH}$ production (compared with proportional scaling with UV). OFR254-70 appears to be less prone to riskier conditions than OFR254-7, since higher $\mathrm{O}_{3}$ favors $\mathrm{HO}_{2}$-to-OH recycling, making $\mathrm{OH}$ more resilient to suppression (Peng et al., 2015).

Under highly risky conditions $\left(\mathrm{H}_{2} \mathrm{O}<0.1 \%\right.$ and $\mathrm{OHR}_{\text {ext }} \geq 100 \mathrm{~s}^{-1}$ for OFR185, and $\mathrm{H}_{2} \mathrm{O}<0.1 \%$ and $\mathrm{OHR}_{\mathrm{ext}}>200 \mathrm{~s}^{-1}$ for OFR254), some saturated carbonyl compounds (e.g., pyruvic acid, methyl ethyl ketone, and hydroxyacetone) have significant photolysis at $254 \mathrm{~nm}$ relative to reactions with $\mathrm{OH}$. This significant relative contribution of photolysis also results from remarkably slow reactions of saturated carbonyl compounds with $\mathrm{OH}$. Although secondary species without $\mathrm{C}=\mathrm{C}$ double bond, e.g., saturated carbonyls, hydroperoxides, and nitrates, can be photolyzed in OFRs at low $\mathrm{H}_{2} \mathrm{O}$ and/or high $\mathrm{OHR}_{\text {ext }}$, their photolysis only proceeds to a $\sim 10-1000$ times smaller extent than ambient photolysis at the same photochemical age (Fig. 6).

Unsaturated carbonyls may have much higher absorption cross sections if their $\mathrm{C}=\mathrm{C}$ bonds are conjugated with carbonyls. However, according to our following analysis, conjugated unsaturated carbonyl compounds do not often cause problems of non-tropospheric photolysis at $254 \mathrm{~nm}$. Car- 


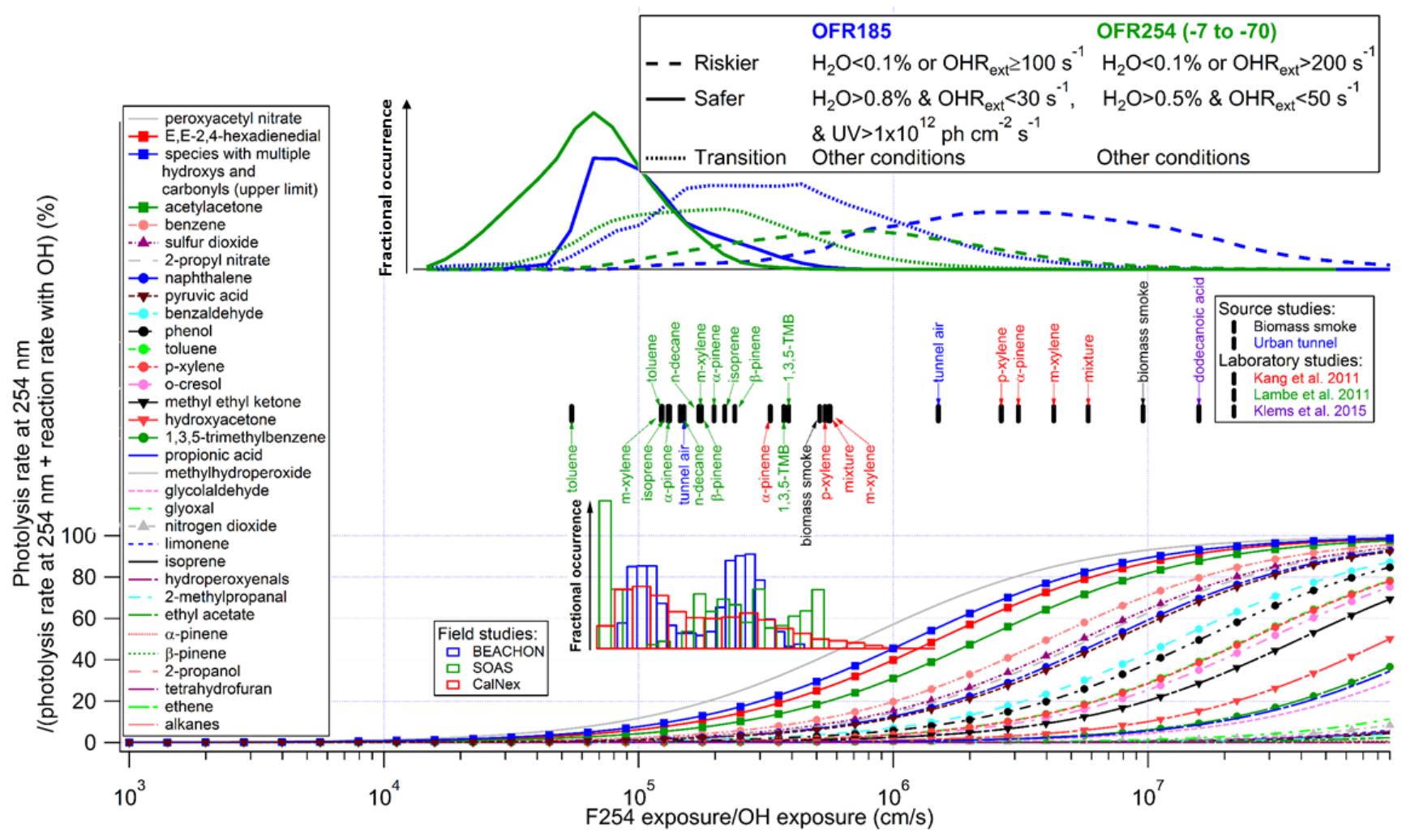

Figure 2. Same format as Fig. 1, but for the fractional importance of the photolysis rate at $254 \mathrm{~nm}$ vs. the reaction rate with $\mathrm{OH}$ as a function of the ratio of exposure to $254 \mathrm{~nm}(\mathrm{~F} 254)$ and $\mathrm{OH}$. The modeled frequency distributions of ratios of $254 \mathrm{~nm}$ photon exposure to $\mathrm{OH}$ exposure under riskier, safer, and transition conditions for OFR185 and OFR254 (-7 to -70) are also shown. The curves of saturated carbonyl compounds and possible highly absorbing oxidation intermediates are highlighted by downward triangles and squares, respectively. The insets show histograms of model-estimated F254/OH exposures for three field studies where OFR185 was used to process ambient air. In addition to source studies of biomass smoke (FLAME-3) and urban tunnel (Tkacik et al., 2014), F254 exposure / OH exposure ratios in two laboratory studies (Kang et al., 2011; Lambe et al., 2011b) are shown in the upper inset. Colored tags indicate species used in the laboratory experiments. The lower and upper limits of F254 exposure / OH exposure ratios in the experiments with a certain source in a certain study are denoted by tags below and above the markers, respectively.

bonyls have $\pi-\pi^{*}$ and $n-\pi^{*}$ transitions. The former corresponds to high cross section (typically $>10^{-18} \mathrm{~cm}^{2}$ ) and typically occurs around or below $200 \mathrm{~nm}$. The latter is forbidden and thus has weak absorption (cross section on the order of $10^{-19} \mathrm{~cm}^{2}$ or lower) and typically occurs around or above $300 \mathrm{~nm}$ (Turro et al., 2009). Conjugation usually does not substantially enhance the absorption of $n-\pi^{*}$ transition, but it does for $\pi-\pi^{*}$ transitions (Turro et al., 2009). As a result, through conjugation, the only reason why cross sections of carbonyls at $254 \mathrm{~nm}$ may be elevated above $10^{-18} \mathrm{~cm}^{2}$ is the redshift of the maximum absorption wavelength of their $\pi-$ $\pi^{*}$ transitions due to conjugation. According to Woodward's rules (Pretsch et al., 2009) and available cross-section data of $\alpha, \beta$-unsaturated carbonyls in Keller-Rudek et al. (2015), a conjugation of at least 3-4 double bonds is required for the excitation at $254 \mathrm{~nm}$ to dominantly correspond to $\pi-\pi^{*}$ transition. Conjugated oxidation intermediates containing at least 3-4 double bonds including $\mathrm{C}=\mathrm{C}$ bond(s) are virtually impossible to form from aliphatic hydrocarbon oxidation in
OFRs. Nevertheless, such intermediates may form via ringopening pathways of aromatic oxidation (Calvert et al., 2002; Atkinson and Arey, 2003; Strollo and Ziemann, 2013). E,E2,4-hexadienedial may be regarded as an example of this type of intermediates. Even under assumption of a unity quantum yield, its fraction of photolysis at $254 \mathrm{~nm}$ is not much higher than that of aromatic precursors (Fig. 2). Therefore, $254 \mathrm{~nm}$ photolysis of conjugated intermediates should not be problematic as long as safer experimental conditions are adopted.

To our knowledge, the only exception that has strong absorption at $254 \mathrm{~nm}$ due to conjugation with $<2$ double bonds are $\beta$-diketones, which may be formed in aliphatic hydrocarbon oxidation, particularly that of long-chain alkanes (Ziemann and Atkinson, 2012). The peculiarity of $\beta$-diketones is that their enol form may have a highly conjugated ring structure due to very strong resonance (Scheme S1) and hence cross sections on the order of $10^{-17} \mathrm{~cm}^{2}$ at $254 \mathrm{~nm}$ (Messaadia et al., 2015). However, even under the assumption of unity quantum yield, the fractional contribution of $254 \mathrm{~nm}$ 
photolysis of acetylacetone (representative of $\beta$-diketones) is only slightly larger than for aromatic VOCs (Fig. 2), since its enol form also contains a $\mathrm{C}=\mathrm{C}$ bond leading to very high reactivity toward $\mathrm{OH}$. Furthermore, we argue that the actual probability that a concrete structural change (in number and type of functional groups, $\mathrm{O} / \mathrm{C}$ ratio, average $\mathrm{C}$ oxidation state, etc.) of $\beta$-diketones resulting from photoexcitation at $254 \mathrm{~nm}$ may be low. As their excitation at $254 \mathrm{~nm}$ corresponds to $\pi-\pi^{*}$ transition, their rigid ring structure likely hinders cyclic structural change at the first singlet excited state $\left(S_{1}\left(\pi, \pi^{*}\right)\right)$ while the biradical structure of the first triplet state $\left(T_{1}\left(\pi, \pi^{*}\right)\right)$ may favor $\mathrm{H}$ shift between two $\mathrm{O}$ atoms, which ends up with the same/similar structure than prior to the $\mathrm{H}$ shift (Scheme S1). Also, the excitation of $\beta$ diketones at $254 \mathrm{~nm}$ may also lead to charge transfer complex formation via direct excitation and/or radiationless transition from a local excited state (Phillips and Smith, 2015), which is likely to result in low quantum yields, as discussed in detail below.

In addition to conjugated species, Phillips and Smith $(2014,2015)$ reported a new type of highly absorbing species that may be formed from VOC oxidation. Although their studies were conducted in the condensed phase, it is likely that the main conclusions of these studies are generally transferable to the gas-phase conditions, since no long-range interactions, which do not exist in normal gases, were involved in these studies. Phillips and Smith $(2014,2015)$ investigated the photoabsorption enhancement of multifunctional oxygenated species in SOA and found that the high absorptivity of these species can largely be explained by transitions toward the electronic states of charge transfer complex formed between hydroxyl groups (donor) and spatially neighboring carbonyl groups (acceptor). They also pointed out that charge transfer complexes of this kind have a continuum of states whose energy levels range from that of local excited states (radiative transition wavelength $<300 \mathrm{~nm}$ ) to very low levels (radiative transition wavelength $>600 \mathrm{~nm}$ ). The latter are insufficient to cause common photochemical reactions. Relaxation through a continuum of states is usually ultrafast according to Fermi's golden rule (Turro et al., 2009), likely leading to low quantum yields of chemical reactions. The low quantum yields may be seen even from species with only one hydroxyl and one carbonyl: the photolysis of 3-hydroxy-3-methyl-2butanone and 4-hydroxy-2-butanone at wavelengths down to $270 \mathrm{~nm}$ has quantum yields around only 0.1 (Bouzidi et al., 2014, 2015). Although measurements of photolysis quantum yield for multifunctional species are challenging and rare, it is reasonable to expect even lower quantum yields for larger and/or highly substituted (by hydroxyl and carbonyl) species, since larger species have more degrees of freedom for relaxation of excited molecules, and more and/or larger complex sites generally lead to more efficient relaxation through a continuum of states, in accordance with common photophysical sense (Sharpless and Blough,
2014). Therefore, even though species with a number of hydroxyls and carbonyls are formed in VOC oxidation and can absorb $>1$ order of magnitude more efficiently at $254 \mathrm{~nm}$ than mono- and difunctional species, they may still have low effective photolysis rates because of low quantum yields.

For this type of species, we estimate an upper limit of the fractional importance of their photolysis at $254 \mathrm{~nm}$. Molar absorption coefficients of charge transfer transitions of organic molecules are usually $\sim 10^{3}-1 \times 10^{4} \mathrm{~L} \mathrm{~mol}^{-1} \mathrm{~cm}^{-1}$, i.e., cross sections of $\sim 3.9 \times 10^{-18}-3.9 \times 10^{-17} \mathrm{~cm}^{2}$ (Foster, 1969). Based on that, it is reasonable to estimate an upper limit of absorption cross sections of charge transfer transitions of $5 \times 10^{-17} \mathrm{~cm}^{2}$. However, photolysis quantum yields of multifunctional species are unlikely to be larger than that of species with only one carbonyl and one hydroxyl, i.e., $\sim 0.1$ (see discussion above). We thus take 0.1 as an upper limit of photolysis quantum yields. Besides, $6 \times 10^{-12} \mathrm{~cm}^{3}$ molecule ${ }^{-1} \mathrm{~s}^{-1}$ can be a conservative estimate of rate constants of multifunctional oxygenated species with $\mathrm{OH}$, as it is roughly an average value for ketones (Atkinson and Arey, 2003), and the enhancement of H-abstraction by hydroxyl groups (Kwok and Atkinson, 1995; Ziemann and Atkinson, 2012) and the fast abstraction of aldehydic $\mathrm{H}$ atoms (Atkinson and Arey, 2003) are completely neglected. With the three estimates combined, the estimated maximum fractional contribution from photolysis at $254 \mathrm{~nm}$ to the fate of multifunctional species (Fig. 2) is close to that of $E, E$ 2,4-hexadienedial and acetylacetone.

The problem of photolysis of oxidation intermediates at $185 \mathrm{~nm}$ is unlikely to be worse than at $254 \mathrm{~nm}$. According to available UV spectra of carbonyl compounds in KellerRudek et al. (2015), $185 \mathrm{~nm}$ is almost always located within the $\pi-\pi^{*}$ transition band, whose maximum cross section is on the order of $10^{-17} \mathrm{~cm}^{2}$. Even if all types of radiative transitions at normal radiation intensity are considered, an approximate upper limit of absorption cross sections is $\sim 10^{-16} \mathrm{~cm}^{2}$ (Evans et al., 2013). However, UV intensity at $185 \mathrm{~nm}$ in the OFR 185 mode is $\sim 100$ times lower than that at $254 \mathrm{~nm}$ (Li et al., 2015). The photolysis rate of oxidation intermediates at $185 \mathrm{~nm}$ should thus be generally smaller than at $254 \mathrm{~nm}$.

Therefore, in summary, photolysis of oxidation intermediates are, to our knowledge, conservatively estimated to be of limited importance relative to their reactions with $\mathrm{OH}$, as long as the experimental conditions are in the safer range. Although studies on photolysis quantum yields of oxidation intermediates are very sparse, we reason, based on the existing studies on this topic and common photophysical and photochemical rules, that the photolysis quantum yields of these species may be lower than the values assumed in this study (e.g., 1 for $E, E$-2,4-hexadienedial and acetylacetone and 0.1 for multifunctional species). As a result, actual rates and relative importance of photolysis might be significantly smaller than the upper limits estimated in our study. 
As discussed for photolysis at $185 \mathrm{~nm}$, in all ambient OFR field studies (BEACHON-RoMBAS, SOAS, and CalNexLA), reactions with $\mathrm{OH}$ dominate over photolysis at $254 \mathrm{~nm}$ (Fig. 2). The fractional consumption of several anthropogenic aromatic VOCs, such as benzene and naphthalene, in the urban CalNex-LA campaign by $254 \mathrm{~nm}$ photolysis is estimated as a few percent under most conditions and at most $\sim 15 \%$. At the BEACHON-RoMBAS and SOAS forested sites, photolysis at $254 \mathrm{~nm}$ should be a negligible contributor to the fate of biogenic VOCs such as isoprene and monoterpenes.

Some laboratory and source studies may have had an appreciable contribution to aromatic species fate from $254 \mathrm{~nm}$ at low $\mathrm{H}_{2} \mathrm{O}$ and/or high $\mathrm{OHR}_{\text {ext }}$. $\mathrm{F} 254_{\exp } / \mathrm{OH}_{\exp }$ in the biomass smoke and urban tunnel source studies (source $\mathrm{OHR}_{\text {ext }}$ up to $\sim 300 \mathrm{~s}^{-1}$; Ortega et al., 2013; Tkacik et al., 2014) and the Kang et al. (2011) laboratory study $\left(\mathrm{H}_{2} \mathrm{O}\right.$ down to $\sim 0.1 \%$ ) can be as high as $10^{6}-10^{7} \mathrm{~cm} \mathrm{~s}^{-1}$. In this range, photolysis of a few aromatic VOCs (e.g., benzene and naphthalene) at $254 \mathrm{~nm}$ could account for $\sim 20-80 \%$ of their destruction.

Note that photolysis of oxidation intermediates also needs to be taken into account. If multifunctional species, $\beta$ diketones, and extensively conjugated species are photolyzed as shown in Fig. 2, these photolyses would be significant in some previous source and laboratory studies examined here, as they were conducted at relatively low $\mathrm{H}_{2} \mathrm{O}$ and/or high $\mathrm{OHR}_{\text {ext }}$. To our knowledge, none of these studies reported a significant photolysis of oxidation intermediates. Klems et al. (2015) attributed large amounts of fragmentation products detected in their OFR experiments with dodecanoic acid to photolysis of peroxy radicals. However, these products may also be at least partially accounted for by photolysis of carbonyls leading to carbon-chain cleavage via Norrish reactions (Laue and Plagens, 2005). The OFR used by Klems et al. (2015) has a different design from the PAM, which is regarded as the base design in this study. Their reactor employs a light source stronger than the PAM's highest lamp setting, with UV at $254 \mathrm{~nm}$ estimated to be $\sim 3 \times 10^{16}$ photons $\mathrm{cm}^{-2} \mathrm{~s}^{-1}(\sim 4$ times the value at the highest lamp setting of the PAM OFR) based on the lamp power and the reactor geometry. Such high UV may even result in significant photolysis of saturated carbonyl intermediates, which are very likely formed in the oxidation of long-chain alkane-like dodecanoic acid.

\subsubsection{Reactions with $\mathrm{OH}$ vs. reactions with $\mathrm{O}\left({ }^{1} \mathrm{D}\right)$ and $\mathbf{O}\left({ }^{3} \mathbf{P}\right)$}

The results for these two radicals are shown in Figs. 3-4. The potential impact of $\mathrm{O}\left({ }^{1} \mathrm{D}\right)$ is smaller than for 185 and $254 \mathrm{~nm}$ photons, due to the low concentration of $\mathrm{O}\left({ }^{1} \mathrm{D}\right)$ in the reactor. Only for methane may reaction with $\mathrm{O}\left({ }^{1} \mathrm{D}\right)$ be significant, because the reaction of methane with $\mathrm{O}\left({ }^{1} \mathrm{D}\right)$ is close to the collision rate, while $\mathrm{CH}_{4}$ is the most resistant
VOC to $\mathrm{H}$-abstraction by $\mathrm{OH}$. This could be important if $\mathrm{CH}_{4}$ was used for $\mathrm{OH}_{\exp }$ calibration under riskier reactor conditions, or if the fate of $\mathrm{CH}_{4}$ is important to the experiment for other reasons. Other VOCs react much faster with $\mathrm{OH}$. As a result, reactions of VOCs (other than $\mathrm{CH}_{4}$ ) with $\mathrm{O}\left({ }^{1} \mathrm{D}\right)$ in all laboratory, field, and source studies previously discussed are almost always negligible. We also note that the ratio of $\mathrm{O}\left({ }^{1} \mathrm{D}\right)_{\exp } / \mathrm{OH}_{\exp }$ in the OFR is actually much lower than in the troposphere (Monks, 2005), except under some riskier conditions. It is believed that the contribution of $\mathrm{O}\left({ }^{1} \mathrm{D}\right)$ to VOC destruction in the atmosphere should be negligible (Calvert et al., 2002), and their relative importance is even lower under most OFR conditions.

Reactions with $\mathrm{O}\left({ }^{3} \mathrm{P}\right)$ are small or negligible contributors to VOC consumption except under extreme riskier conditions. Unless at low $\mathrm{H}_{2} \mathrm{O}(<0.1 \%)$ and very high external $\mathrm{OH}$ reactivity $\left(\sim 1000 \mathrm{~s}^{-1}\right)$, VOC consumption by $\mathrm{O}\left({ }^{3} \mathrm{P}\right)$ cannot be larger than $10 \%$ of that by $\mathrm{OH}$ (Figs. 4 and S4). This results from both very low concentrations of $\mathrm{O}\left({ }^{3} \mathrm{P}\right)$ and relatively low reactivity compared to that of $\mathrm{OH}$. Among the species that we examine, biogenic VOC consumption may have some contribution from $\mathrm{O}\left({ }^{3} \mathrm{P}\right)$ under the abovementioned riskier conditions, due to the higher reactivity of double bonds in these species with $\mathrm{O}\left({ }^{3} \mathrm{P}\right)$. For example, $\alpha$-pinene in the mixture experiments in Kang et al. (2011) may have had a $\sim 5 \%$ contribution from $\mathrm{O}\left({ }^{3} \mathrm{P}\right)$. Similarly to $\mathrm{O}\left({ }^{1} \mathrm{D}\right)$, $\mathrm{O}\left({ }^{3} \mathrm{P}\right)_{\exp } / \mathrm{OH}_{\exp }$ in the troposphere (Calvert et al., 2002) is higher than in the OFR except for riskier conditions. Thus the relative importance of both $\mathrm{O}\left({ }^{1} \mathrm{D}\right)$ and $\mathrm{O}\left({ }^{3} \mathrm{P}\right)$ to $\mathrm{OFR}$ chemistry is typically lower than in the troposphere.

\subsubsection{Reactions with $\mathrm{OH}$ vs. reactions with $\mathrm{O}_{3}$}

Reaction with $\mathrm{O}_{3}$ is a major, even dominant pathway of the consumption of many biogenic VOCs in the troposphere. However, it is of interest to quantify the relative importance of $\mathrm{OH}$ vs. $\mathrm{O}_{3}$ across OFR experiments (Figs. 5 and S5). This allows comparison with the relative importance in the troposphere, as well as potentially designing experiments where the relative influence of $\mathrm{O}_{3}$ is minimized or adjusted as desired.

A large amount of $\mathrm{O}_{3}$ is injected into OFR254, and $\mathrm{O}_{3}$ concentration in that type of reactor does not change much with UV flux (negligibly under most conditions and up to a factor of $\sim 2$ at high $\mathrm{H}_{2} \mathrm{O}$ and UV; Peng et al., 2015). Since $\mathrm{OH}_{\text {exp }}$ is proportional to UV flux, as UV decreases, $\mathrm{OH}_{\text {exp }}$ is lowered and the fractional species destruction by $\mathrm{O}_{3}$ increases. In OFR $185, \mathrm{O}_{3}$ production is almost linearly dependent on $\mathrm{UV}$, while a significant portion of $\mathrm{OH}$ production has a quadratic relationship with UV. Thus $\mathrm{OH}$ increases faster with increasing UV than $\mathrm{O}_{3}$. Therefore, lower UV in OFR185 also leads to a higher relative importance of $\mathrm{O}_{3}$ for VOC consumption.

The distribution of $\mathrm{O}_{3 \exp } / \mathrm{OH}_{\exp }$ expected for the troposphere was obtained from the GISS ModelE2 climate 


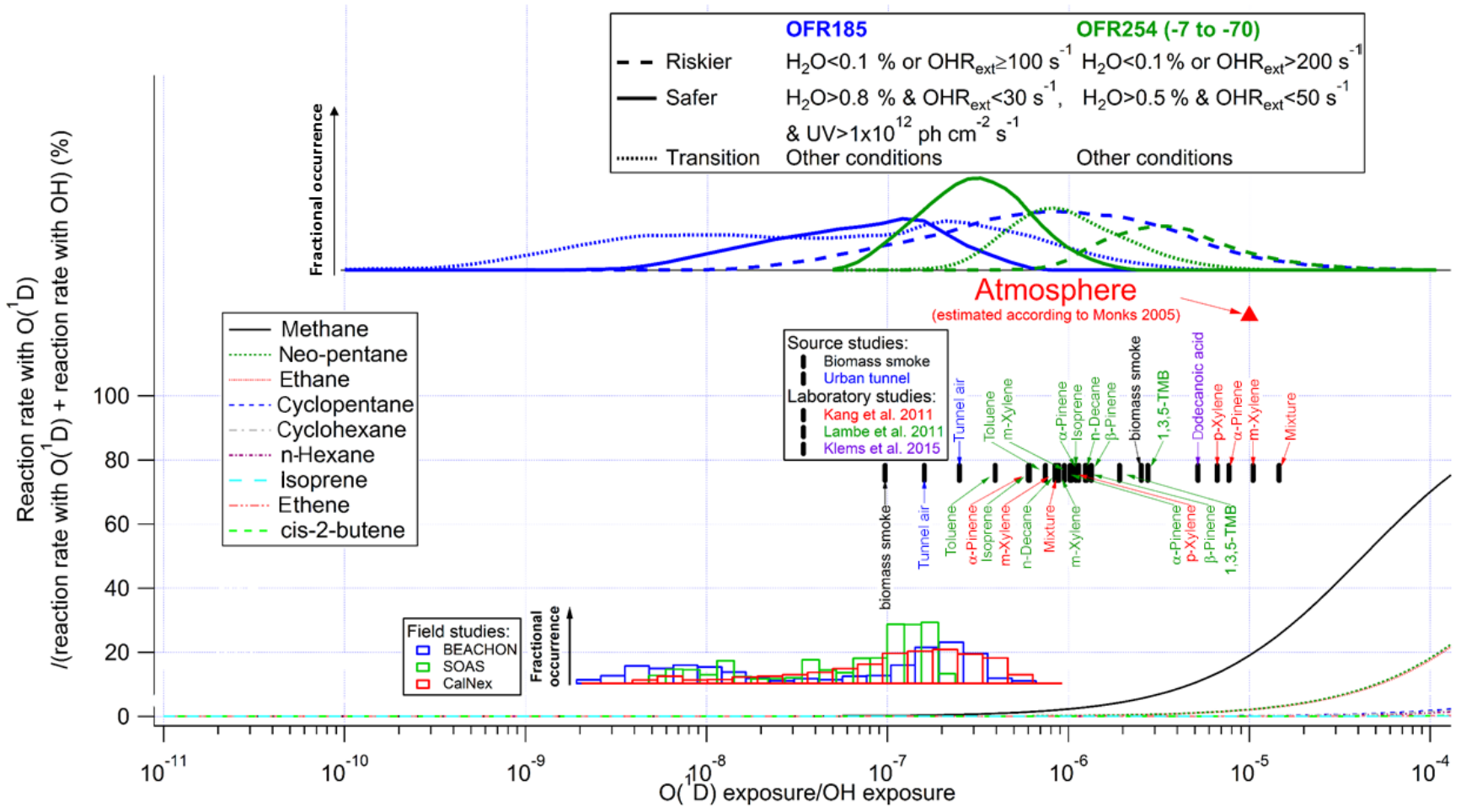

Figure 3. Same format as Fig. 2 but for the ratio of the reaction rate with $\mathrm{O}\left({ }^{1} \mathrm{D}\right)$ vs. $\mathrm{OH}$ as a function of the relative exposure to $\mathrm{O}\left({ }^{1} \mathrm{D}\right)$ and $\mathrm{OH}$. A typical value of the relative exposure of $\mathrm{O}\left({ }^{1} \mathrm{D}\right)$ and $\mathrm{OH}$ in the troposphere estimated according to Monks (2005) is also shown.

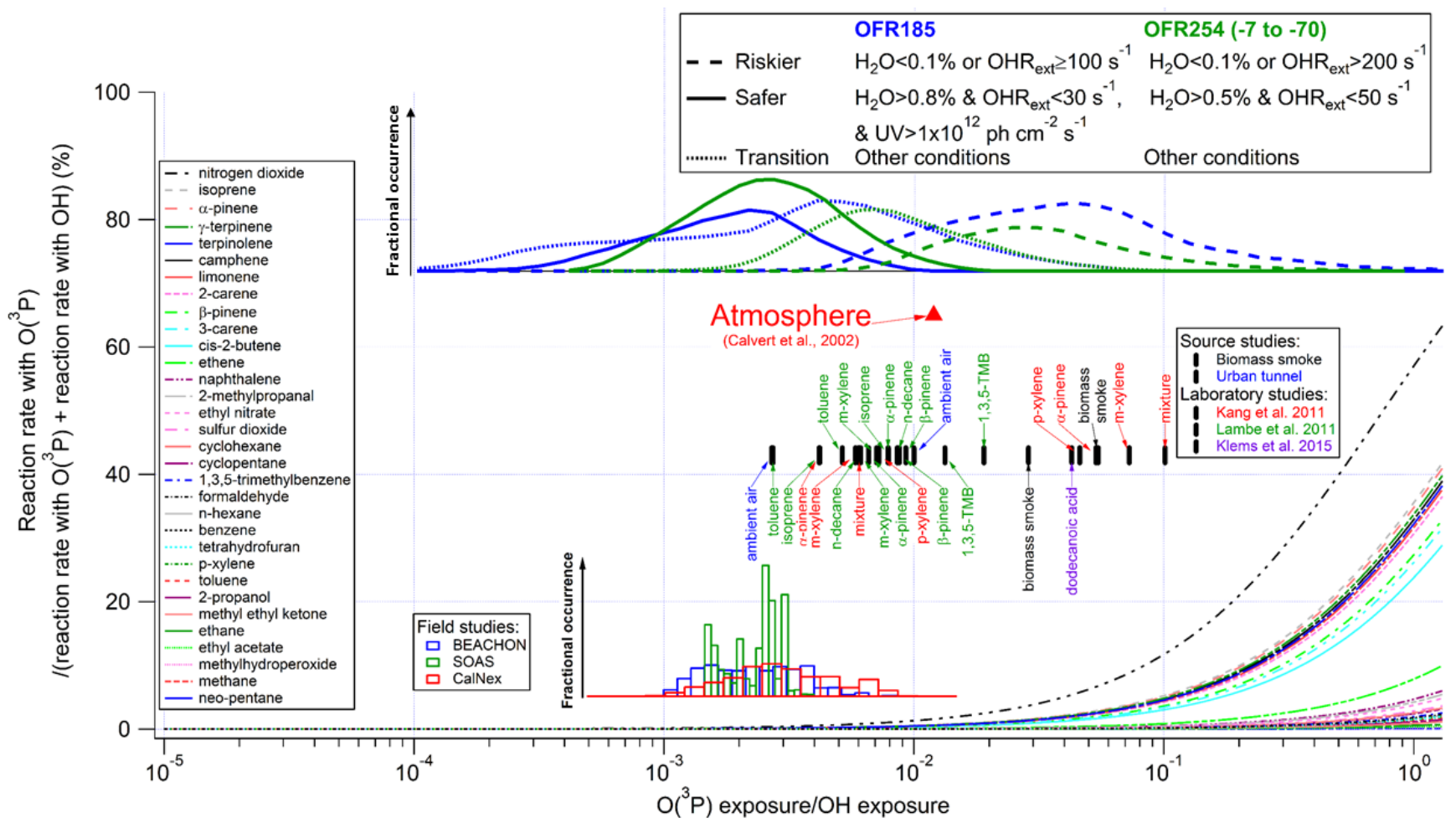

Figure 4. Same format as Fig. 3 but for the ratio of the reaction rate with $\mathrm{O}\left({ }^{3} \mathrm{P}\right)$ vs. $\mathrm{OH}$ as a function of the relative exposure of $\mathrm{O}\left({ }^{3} \mathrm{P}\right)$ and $\mathrm{OH}$. A typical value of the relative exposure of $\mathrm{O}\left({ }^{3} \mathrm{P}\right)$ and $\mathrm{OH}$ in the troposphere from Calvert et al. (2002) is also shown. 


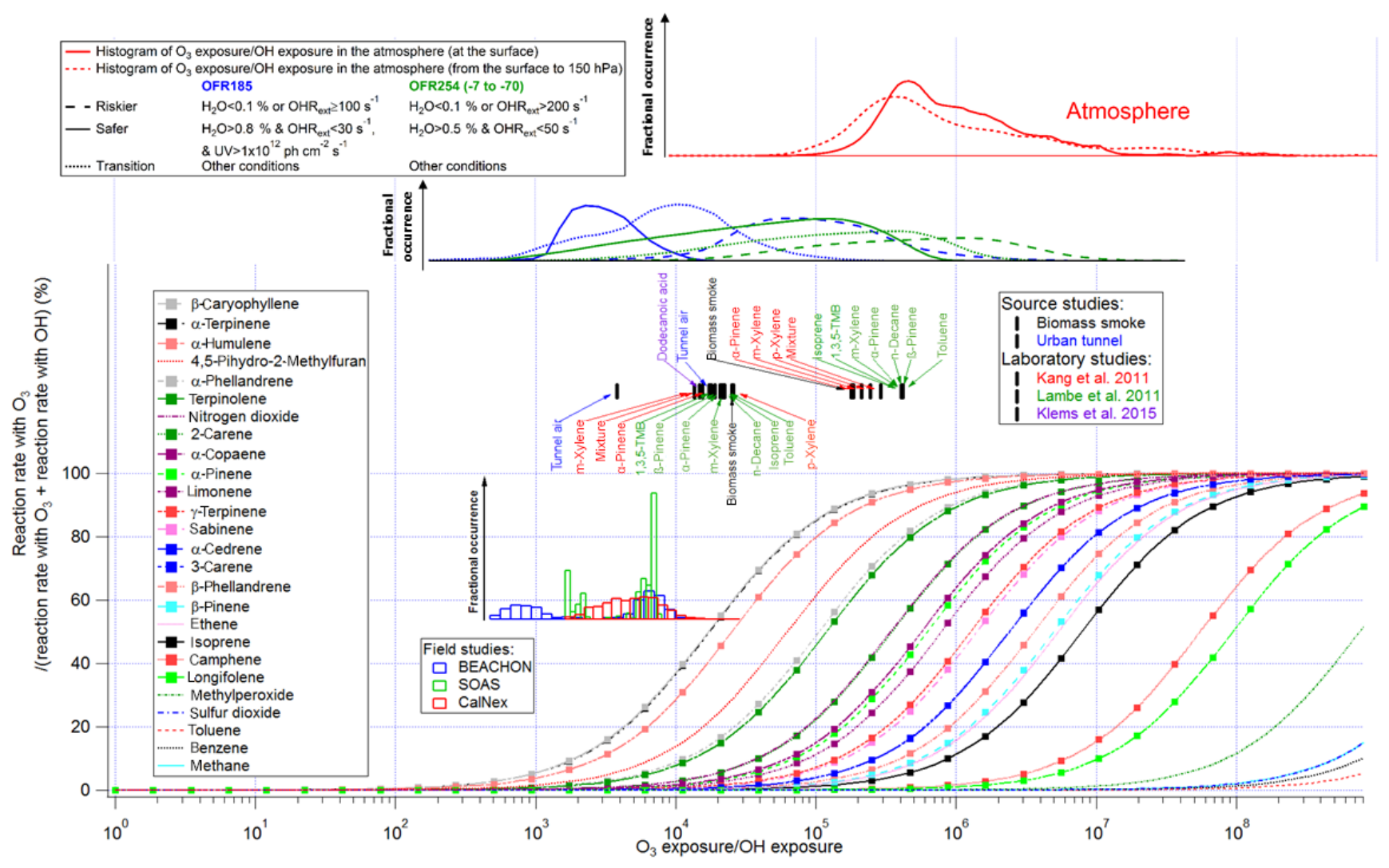

Figure 5. Same format as Fig. 2 but for the fractional importance of the reaction rate with $\mathrm{O}_{3}$ vs. $\mathrm{OH}$ as a function of the relative exposure of $\mathrm{O}_{3}$ and $\mathrm{OH}$. The curves of biogenics are highlighted by squares. Also shown are modeled distributions of the relative exposure of $\mathrm{O}_{3}$ and $\mathrm{OH}$ at the Earth's surface (solid line) and throughout the column from the surface to a height with a pressure of $150 \mathrm{hPa}$ (dashed line). The distributions were calculated from the mean daily concentrations of $\mathrm{O}_{3}$ and $\mathrm{OH}$ as simulated by the GISS ModelE2.

model (Schmidt et al., 2014) and is estimated as the ratio of the simulated daily mean concentration of $\mathrm{O}_{3}$ and $\mathrm{OH}$ on a horizontal grid of $2^{\circ}$ in latitude and $2.5^{\circ}$ in longitude for the year 2000. Interestingly, the simulated relative importance of $\mathrm{O}_{3}$ to $\mathrm{OH}$ in the troposphere is higher than when OFRs are operated under safer conditions, and similar to OFRs when they are operated under riskier conditions (Figs. 5 and S5). In those cases, a number of biogenic VOCs can be significantly consumed by $\mathrm{O}_{3}$. In particular, some monoterpenes (e.g., $\alpha$-terpinene) and sesquiterpenes (e.g., $\beta$ caryophyllene) have a fractional reaction with $\mathrm{O}_{3}$ close to $100 \%$ in the troposphere. In contrast to biogenics, reactions with $\mathrm{O}_{3}$ do not play any role in the consumption of most anthropogenic VOCs, e.g., benzene, toluene, and alkanes. Besides, ozonolysis of saturated oxidation intermediates (e.g., carbonyls and alcohols) is minor or negligible in both OFRs and the atmosphere, since they react with $\mathrm{OH}$ at $\sim 10^{-13}$ $10^{-11} \mathrm{~cm}^{3}$ molecule ${ }^{-1} \mathrm{~s}^{-1}$ while their ozonolysis rate constants are $<10^{-20} \mathrm{~cm}^{3}$ molecule $\mathrm{s}^{-1} \mathrm{~s}^{-1}$ (Atkinson and Arey, 2003). However, unsaturated oxidation intermediates may have larger contributions from $\mathrm{O}_{3}$ because of $\mathrm{C}=\mathrm{C}$ bonds. In particular, dihydrofurans, possible intermediates of satu- rated hydrocarbon oxidation (Ziemann and Atkinson, 2012; Aimanant and Ziemann, 2013), may be predominantly oxidized by $\mathrm{O}_{3}$ in the troposphere. In OFR254, they can still have significant contributions from $\mathrm{O}_{3}$ even outside riskier conditions.

An experimentalist may be interested in obtaining an $\mathrm{O}_{3 \exp } / \mathrm{OH}_{\exp }$ in an OFR close to ambient values, which requires lower $\mathrm{H}_{2} \mathrm{O}$ and higher $\mathrm{OHR}_{\text {ext }}$ conditions, although care should be taken to avoid other non-tropospheric reactions under those conditions. However, one may want to study $\mathrm{OH}$-dominated chemistry and thus want to avoid significant ozonolysis of VOCs to reduce the complexity of VOC fate. This is analogous to the addition of excess NO to suppress $\mathrm{O}_{3}$ in some chamber experiments. In this case the OFRs should be operated under opposite conditions, i.e., high $\mathrm{H}_{2} \mathrm{O}$, high UV, and low $\mathrm{OHR}_{\text {ext }}$. This strategy enhancing $\mathrm{OH}_{\text {exp }}$ is effective for most VOCs, except those with the highest $k_{\mathrm{O}_{3}} / k_{\mathrm{OH}}$ ratios, e.g., $\alpha$-terpinene and $\beta$ caryophyllene. To further decrease the importance of reactions of VOC with $\mathrm{O}_{3}$, it is necessary to lower the $\mathrm{O}_{3}$ concentration. For OFR254, one can inject less $\mathrm{O}_{3}$ into the reactor and increase the UV lamp setting. The comparison between 


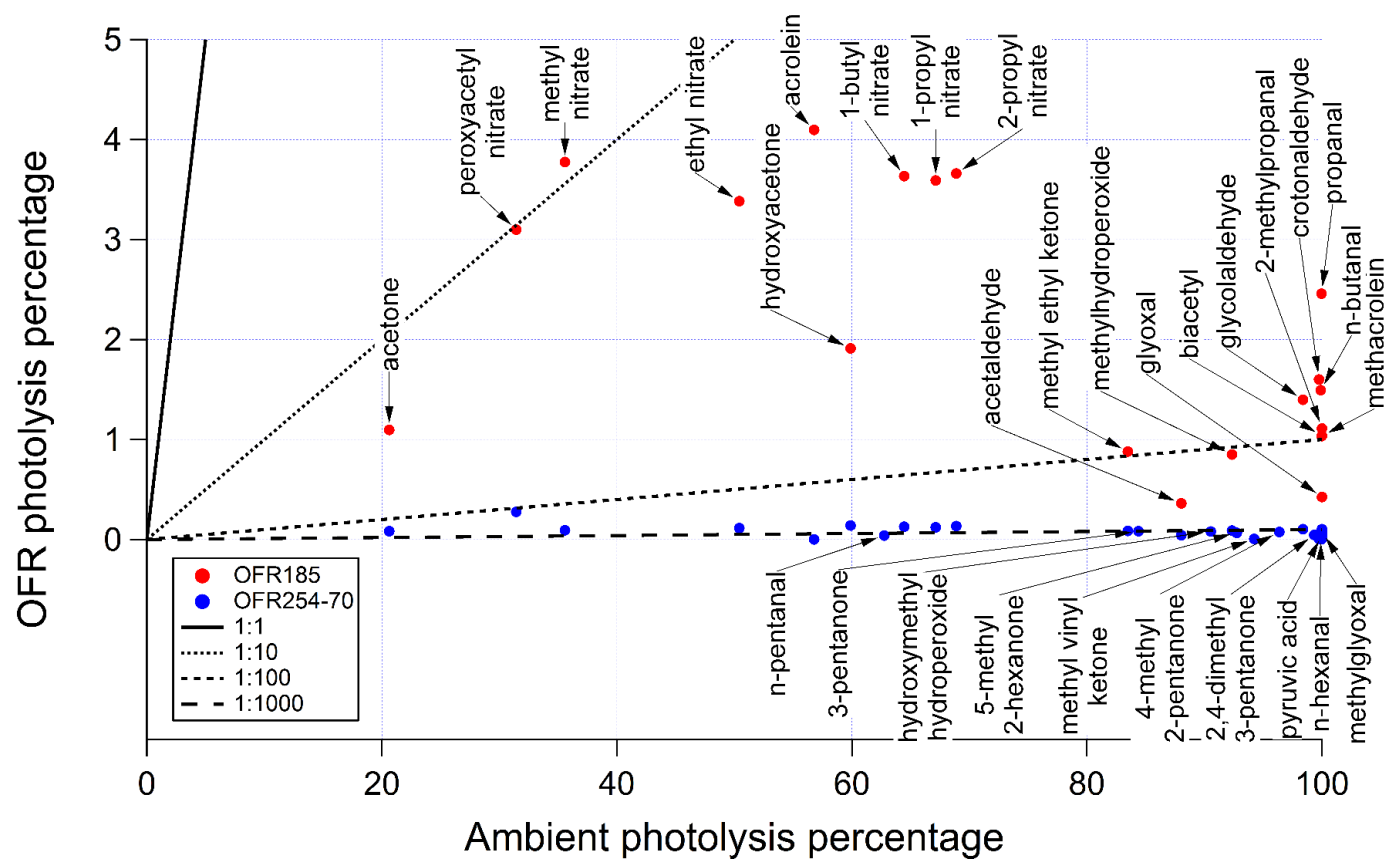

Figure 6. Ambient photolysis fractions of secondary species in a week (calculated from photolysis rates reported in Hodzic et al., 2015) vs. photolysis fractions of those species in OFR185 and OFR254-70 when reaching the same photochemical age (ambient OH concentration of $1.5 \times 10^{6}$ molecules $\mathrm{cm}^{-3}$ assumed) under conditions of $44 \%$ relative humidity (water vapor mixing ratio of $1.4 \%$ ) and $25 \mathrm{~s}^{-1}$ initial

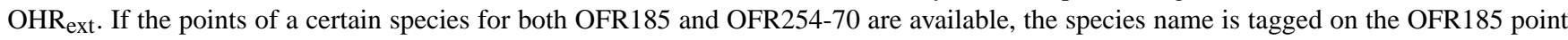
(downward arrow); otherwise it is tagged on the OFR254-70 point (upward arrow). The $1: 1,1: 10,1: 100$, and $1: 1000$ lines are also shown for comparison.

OFR254-70 and OFR254-7 in Fig. S5 demonstrates this approach. For OFR185, we propose another strategy, i.e., lowering $\mathrm{O}_{2}$ concentration in the reactor. This decreases $\mathrm{O}_{3}$ production but affects $\mathrm{OH}$ production to a much lesser extent, thanks to the major $\mathrm{OH}$ production by $\mathrm{H}_{2} \mathrm{O}$ photolysis. We simulate the OFR185 cases with $2 \% \mathrm{O}_{2}$ and observe that VOC ozonolysis can be excluded at high $\mathrm{H}_{2} \mathrm{O}$ and high UV (Fig. S5).

Among the literature OFR studies, the field studies employing OFRs in urban and forested areas all operated under $\mathrm{O}_{3 \exp } / \mathrm{OH}_{\exp }$ values 100 times lower than in the atmosphere. In these field studies reaction of almost all VOCs with $\mathrm{O}_{3}$ can be neglected, except for the most reactive biogenics with $\mathrm{O}_{3}$, e.g., $\alpha$-terpinene and $\beta$-caryophyllene. The source study in an urban tunnel of Tkacik et al. (2014) operated under similar conditions. Some laboratory studies using OFR254 (Kang et al., 2011; Lambe et al., 2011b) as well as the biomass smoke source study (Ortega et al., 2013) operated at $\mathrm{O}_{3 \exp } / \mathrm{OH}_{\exp }$ close to tropospheric values, because the injected $\mathrm{O}_{3}$ plays a key role for OFR254 studies and the biomass smoke experiments were conducted at high $\mathrm{OHR}_{\text {ext }}$. Nevertheless, only $\alpha$-pinene and $\beta$-pinene, both biogenics, are significantly consumed by $\mathrm{O}_{3}$ in these studies. Another OFR254 study, Klems et al. (2015), had $\mathrm{O}_{3 \exp } / \mathrm{OH}_{\exp }$ significant lower than tropospheric values, since the initial $\mathrm{O}_{3}$ in their experiment was only $2 \mathrm{ppm}$, and the UV light in their experiment was stronger than our lamps' highest setting and further reduced effective $\mathrm{O}_{3}$.

\subsubsection{Reactions with ${ }^{1} \mathrm{O}_{2}$ and $\mathrm{HO}_{2}$}

Singlet oxygen, ${ }^{1} \mathrm{O}_{2}$, can be produced in various ways in OFRs (Calvert et al., 2002; Ono et al., 2014) and react with alkenes at appreciable rate constants $\left(\sim 10^{-17}\right.$ $10^{-14} \mathrm{~cm}^{3}$ molecule ${ }^{-1} \mathrm{~s}^{-1}$; Huie and Herron, 1973; Eisenberg et al., 1986). We estimate ${ }^{1} \mathrm{O}_{2}$ concentration by the expression proposed by Ono et al. (2014). Only at the lowest $\mathrm{H}_{2} \mathrm{O}$, the highest lamp setting, and the highest $\mathrm{OHR}_{\text {ext }}$ in this study (Table 1), may the most reactive alkene (endocyclic conjugated dienes, e.g., cyclopentadiene, $\alpha$-terpinene, and $\alpha$-phellandrene) have $>10 \%$ contribution from ${ }^{1} \mathrm{O}_{2}$ to their fate. For all other species and under all other conditions, reactions of VOCs with ${ }^{1} \mathrm{O}_{2}$ are negligible. Thus, this reactant is not discussed further in the present work.

$\mathrm{HO}_{2}$ is a major radical in the OFR chemistry. However, it is much less reactive than $\mathrm{OH}$ toward VOCs. Typically, the rate constants of reactions of $\mathrm{HO}_{2}$ with alkenes are smaller than $10^{-20} \mathrm{~cm}^{3}$ molecule ${ }^{-1} \mathrm{~s}^{-1}$ at room temperature, and those with almost all saturated VOCs (except aldehydes and ketones) are even smaller (Tsang, 1991; Baulch et al., 1992, 2005). Therefore, we briefly discuss reactions of $\mathrm{HO}_{2}$ with aldehydes and ketones and neglect those with all other VOCs 
in this study. Ketones react with $\mathrm{HO}_{2}$ at rate constants on the order of $10^{-16} \mathrm{~cm}^{3}$ molecule ${ }^{-1} \mathrm{~s}^{-1}$ or lower (Gierczak and Ravishankara, 2000; Cours et al., 2007). Therefore, only at low $\mathrm{H}_{2} \mathrm{O}$, low $\mathrm{UV}$, and high $\mathrm{OHR}_{\text {ext }}$, the reaction of acetone with $\mathrm{HO}_{2}$ may compete with that with $\mathrm{OH}$. The same is likely true for the reactions of acetaldehyde and larger aldehydes with $\mathrm{HO}_{2}$, as their rate constants are likely to be around or less than $1 \times 10^{-14} \mathrm{~cm}^{3}$ molecule ${ }^{-1} \mathrm{~s}^{-1}$ (da Silva and Bozzelli, 2009). Formaldehyde is the only stable carbonyl compound that may react with $\mathrm{HO}_{2}$ (rate constant: $7.9 \times 10^{-14} \mathrm{~cm}^{3}$ molecule ${ }^{-1} \mathrm{~s}^{-1}$; Ammann et al., 2015) at a rate competing with that with $\mathrm{OH}$ under conditions that are not low $\mathrm{H}_{2} \mathrm{O}$, low $\mathrm{UV}$, and high $\mathrm{OHR}_{\text {ext }}$. Note that the reaction of formaldehyde with $\mathrm{HO}_{2}$ is also significant in the atmosphere (Pitts and Finlayson, 1975; Gäb et al., 1985). However, its product, hydroxymethylperoxy radical, dominantly undergoes decomposition via thermal reaction and photolysis (Kumar and Francisco, 2015), compared to the hydroxymethyl hydroperoxide formation pathway via a further reaction with $\mathrm{HO}_{2}$ (Ziemann and Atkinson, 2012). Even if hydroxymethyl hydroperoxide is produced in appreciable amounts, in the high-OH environment of OFRs, this species can be easily predicted to convert into formic acid (Francisco and Eisfeld, 2009) and eventually $\mathrm{CO}_{2}$. All these products have very few interactions with other VOCs and hence should not significantly perturb the reaction system of OFRs.

\subsubsection{Overall contribution of non-OH reactants to gas-phase chemistry}

In this section we summarize the combined effect of all non-OH reactants to VOC consumption. However, we can no longer use $\mathrm{X}_{\exp } / \mathrm{OH}_{\exp }$ to express total non-OH VOC consumption as for individual reactants. Total non-OH VOC consumption is thus discussed case by case.

In the explored range of conditions (i.e., $\mathrm{H}_{2} \mathrm{O}, \mathrm{UV}$, $\mathrm{OHR}_{\text {ext }}$, and initial $\mathrm{O}_{3}$ for OFR254), there are obviously conditions where all non-OH fates of VOCs are negligible. Most simply, the highest $\mathrm{H}_{2} \mathrm{O}$ and UV in this study and a very small non-zero $\mathrm{OHR}_{\text {ext }}$ result in a VOC consumption nearly $100 \%$ by $\mathrm{OH}$, regardless of the VOC type (Table S6). Lowering UV can make non-OH contribution even smaller for OFR185, but not for OFR254. This difference occurs because $\mathrm{OH}$ production is reduced while $\mathrm{O}_{3}$ roughly remains at the same level in OFR254, leading to enhanced relative contribution from $\mathrm{O}_{3}$ to the fate of biogenics. At the lowest nonzero UV in the PAM reactor $\left(7.9 \times 10^{11}\right.$ photons $\mathrm{cm}^{-2} \mathrm{~s}^{-1}$ at $185 \mathrm{~nm} ; 2.0 \times 10^{14}$ photons $\mathrm{cm}^{-2} \mathrm{~s}^{-1}$ at $254 \mathrm{~nm}$ ) of Li et al. (2015), the fractional destructions of $\alpha$-pinene (representative of biogenic VOCs) by $\mathrm{O}_{3}$ are 21 and $4.2 \%$ in OFR254-70 and OFR254-7, respectively. Other OFR designs may reach lower UV, e.g., the "low UV" case defined in this study $\left(1.0 \times 10^{11}\right.$ photons $\mathrm{cm}^{-2} \mathrm{~s}^{-1}$ at $185 \mathrm{~nm}$; $4.2 \times 10^{13}$ photons $\mathrm{cm}^{-2} \mathrm{~s}^{-1}$ at $\left.254 \mathrm{~nm}\right)$. At these UV levels, the fate of $\alpha$-pinene by $\mathrm{O}_{3}$ further increases to 44 and $13 \%$ in OFR254-70 and OFR254-7, respectively.

However, non-OH reactants can dominate VOC fate under opposite conditions that lead to low $\mathrm{OH}$ production and strong $\mathrm{OH}$ suppression. At the lowest $\mathrm{H}_{2} \mathrm{O}$ and $\mathrm{UV}$ and the highest $\mathrm{OHR}_{\text {ext }}$ in this study, $>95 \%$ of $\alpha$-pinene and $\sim 80 \%$ of toluene are consumed by non-OH reactants in OFR185. In OFR254, almost all $\alpha$-pinene has non-OH fate while non-OH fate of toluene is still minor or negligible. If OFRs are operated at the low UV setting from the PAM by Li et al. (2015), $\sim 8$ times higher the lowest UV in this study, the situation hardly changes, as a very large $\mathrm{OH}$ suppression persists. Nevertheless, if UV is increased to the highest level, non-OH fate of $\alpha$-pinene is lowered to $\sim 60-70 \%$ and that of toluene in OFR1 85 decreases to $24 \%$. When $\mathrm{H}_{2} \mathrm{O}$ is at the highest level, non-OH fate is systematically lower than at low $\mathrm{H}_{2} \mathrm{O}$ in all types of OFRs. In particular, the HHV case has non-OH fates of $\alpha$-pinene only up to $\sim 10 \%$ and negligible non-OH fates of toluene, despite very high $\mathrm{OHR}_{\text {ext }}$.

We also summarize VOC fate for key laboratory, source, and field studies examined in the present work in Fig. 7. For each case, the fate of one or a few typical VOCs is investigated. In laboratory studies, Kang et al. (2011) performed experiments with a mixture of $\alpha$-pinene, m-xylene, and $\mathrm{p}$ xylene, and one of experiments by Lambe et al. (2011b) used biogenics ( $\alpha$-pinene and isoprene, respectively) as precursors. In both cases, $\mathrm{O}_{3}$ plays a role in the fate of biogenics when $\mathrm{H}_{2} \mathrm{O}$ is low (Kang et al., 2011), or OHR ext is high and UV is low (Lambe et al., 2011b), as shown in Fig. 7. The fate of isoprene by $\mathrm{O}_{3}$ is less significant despite the very high $\mathrm{OHR}_{\text {ext }}$, because isoprene, compared to $\alpha$-pinene, is more reactive with $\mathrm{OH}$ and less reactive with $\mathrm{O}_{3}$. Besides, $\mathrm{O}\left({ }^{3} \mathrm{P}\right)$ contributes up to a few percent to the fate of biogenics. In the literature experiments performed at a higher $\mathrm{H}_{2} \mathrm{O}$ (Kang et al., 2011) or a higher UV (Lambe et al., 2011b), non-OH fate of both VOCs significantly decreases because

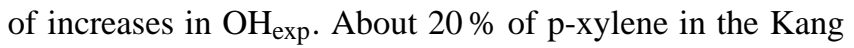
et al. (2011) mixture experiment at very low $\mathrm{H}_{2} \mathrm{O}$ may be destroyed by $254 \mathrm{~nm}$ photons, under the assumption of unity quantum yield. Other laboratory study cases with aromatics have lower non-OH fates because of higher $\mathrm{H}_{2} \mathrm{O}$. N-decane in one of Lambe et al.'s experiments and dodecanoic acid in the Klems et al. (2015) study are consumed $\sim 100 \%$ by $\mathrm{OH}$, as these alkane(-like) species neither react rapidly with $\mathrm{O}_{3}$, nor absorb UV efficiently. However, as previously discussed, some carbonyl compounds may be formed and significantly photolyzed at $254 \mathrm{~nm}$ in the Klems et al. (2015) experiments, although the huge complexity of intermediates and limited knowledge of reaction mechanisms prevents a quantitative assessment of the fate of carbonyl intermediates by photons at $254 \mathrm{~nm}$.

Source and field studies usually have highly complex precursors. For the urban tunnel study (Tkacik et al., 2014) and the CalNex-LA study in the Los Angeles basin (Ortega et al., 2015), we choose toluene as a representative of 

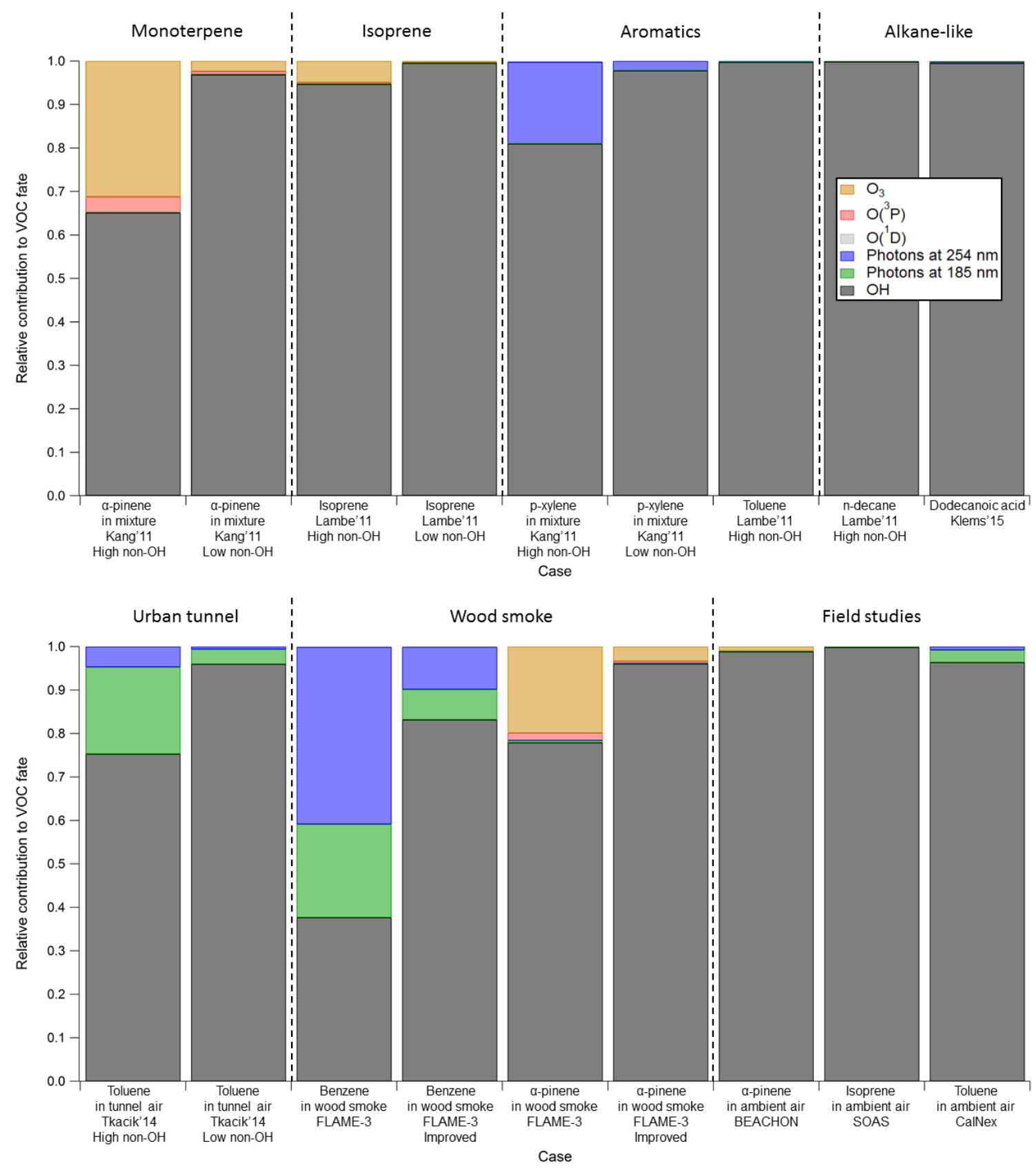

Figure 7. VOC fate in several representative cases of the laboratory, source, and field studies examined in this work. More details on VOC fate in these studies can be found in Table S4.

aromatic species, as these are major anthropogenic VOCs and SOA precursors in urban environment (Dzepina et al., 2009; Borbon et al., 2013; Hayes et al., 2015; Jathar et al., 2015). Although alkanes are also major anthropogenic VOCs, their non-OH fate is not quantitatively assessed for the same reason as discussed for dodecanoic acid in the Klems et al. (2015) experiment. For the smoke aging study, FLAME-3 (Ortega et al., 2013), we select benzene and $\alpha$ pinene, which are important VOCs in biomass burning emissions (Warneke et al., 2011). For the BEACHON-RoMBAS and SOAS studies at forested sites, $\alpha$-pinene and isoprene are chosen, respectively, as they are major emitted biogenic VOCs at those corresponding sites. Both the urban tunnel and FLAME-3 studies have aromatic precursors significantly photolyzed at 185 and $254 \mathrm{~nm}$ (assuming quantum yield $=1$ ) under the conditions of high source concentrations (Fig. 7). The toluene fate by UV in the tunnel study is less substantial than that of benzene in FLAME-3, since $\mathrm{NO}_{x}$, the largest fraction of external $\mathrm{OH}$ reactant in the tunnel study, is converted into $\mathrm{HNO}_{3}$ very rapidly (Li et al., 2015) and does not 
further suppress $\mathrm{OH}$. In the cases of lower $\mathrm{OHR}_{\text {ext }}$ (e.g., the tunnel experiments with low source concentration and CalNex), toluene is dominantly consumed by $\mathrm{OH}$. It also holds for biogenic VOCs that non-OH fate decreases with decreasing $\mathrm{OHR}_{\text {ext }}$ due to less $\mathrm{OH}$ suppression. The non-OH fate of $\alpha$-pinene in FLAME-3, dominated by reaction with $\mathrm{O}_{3}$, is larger than $20 \%$, while the non-OH fates of $\alpha$-pinene in BEACHON-RoMBAS and of isoprene in SOAS are both negligible, since $\mathrm{OHR}_{\text {ext }}$ in the former study is $>10$ times higher than in the latter two studies.

\subsection{SOA photolysis}

Recently, photolysis in the UV range has been found to be a potentially significant sink of some types SOA in the troposphere (Updyke et al., 2012; Lambe et al., 2013; Liu et al., 2013, 2015; Hodzic et al., 2015; Wong et al., 2015; Romonosky et al., 2016). It is necessary to also investigate SOA photolysis in OFRs, as photons used in OFRs are highly energetic and non-tropospheric. UV extinction due to aerosol optical scattering and in-particle absorption under OFR conditions is generally negligible (Hodzic et al., 2015). For simplicity, we estimate photodegradation ratios of various SOA component surrogates as well as several SOA samples whose absorptivity was measured in previous studies (Updyke et al., 2012; Lambe et al., 2013; Liu et al., 2013; Romonosky et al., 2016) (Fig. 8) under the assumption of unity quantum yield to obtain upper limits of photodegradation ratios, as well as under the assumption of lower (0.1 and 0.01) quantum yields.

Most SOA functional groups are oxygenated (e.g., peroxides, carbonyls, carboxylic acids, alcohols). The absorption cross sections of most of these functional groups are too low at 185 and $254 \mathrm{~nm}$ given the OFR residence time and UV light intensity, leading to a small contribution of photolysis to SOA degradation (Fig. 8). For example, glycolaldehyde has a negligible fractional contribution of photolysis except at the highest lamp setting, when only $\sim 5 \%$ of this species photolyzes at each wavelength. Species (e.g., isoprene) with conjugated double bonds as efficient chromophores will not be present in SOA because of their high reactivity with $\mathrm{OH}$ and $\mathrm{O}_{3}$. Nitrate groups may have $\mathrm{a} \sim 30 \%$ contribution from photolysis at the highest UV settings and a negligible contribution at intermediate or low UV settings.

Aromatic rings are more resistant to $\mathrm{OH}$ attack and usually strongly absorb UV light. Under our assumptions, the photolysis of some aromatic SOA components (e.g., o-cresol at $185 \mathrm{~nm}$ and naphthalene at $254 \mathrm{~nm}$ ) is already important at medium UV flux. At the highest lamp setting, most aromatics in SOA would be destroyed if the quantum yields are indeed near unity. However, as previously discussed, photolysis quantum yields of aromatics may be significantly lower than 1. This is more probable in the condensed phase (Damschen et al., 1978; Baker et al., 2015) than in the gas phase, as quenching processes in the condensed-phase matrix are usually much more efficient than through gas-phase molecular collisions. It has recently been reported that photolysis quantum yields of aromatics in SOA were low under UVB irradiation (Romonosky et al., 2015). Although the range and relevance of the species investigated in that study are limited, it is reasonable to assume low quantum yield for aromatic photolysis in SOA at 185 and $254 \mathrm{~nm}$.

Wong et al. (2015) conducted $\alpha$-pinene-derived SOA photolysis experiments in a chamber under UVB irradiation (down to $284 \mathrm{~nm}$ ). They observed at $85 \% \mathrm{RH} \sim 30 \%$ SOA photolyzed after $>30$ min irradiation and a photolysis quantum yield of $\sim 1$ during the first $10 \mathrm{~min}$. However, in OFRs such a high SOA photodegradation percentage would not occur, since the Wong et al. (2015) experiments had a high photon flux $\left(\sim 4 \times 10^{15}\right.$ photons $\left.\mathrm{cm}^{-2} \mathrm{~s}^{-1}\right)$ and a long irradiation time, and hence a photon flux exposure that is $\sim 5$ times that at the highest lamp setting in the OFRs modeled in our work. According to the measurements of Wong et al. (2015), a photolysis fraction of $\sim 6 \%$ would be expected for this type of SOA in our OFRs under the highest UV flux, with lower percentages at lower UV settings. In addition, the approximate unity quantum yield observed in Wong et al. (2015) may be due to (hydro)peroxides in $\alpha$-pinene-derived SOA, since peroxides have high photolysis quantum yields (Goldstein et al., 2007; Epstein et al., 2012), while other functional groups (i.e., mainly hydroxyl and carbonyl) in oxygenated species in SOA are unlikely to have for reasons discussed below.

Note that a simple addition of absorptivities of different functional groups may not explain SOA absorptivity (Phillips and Smith, 2015). According to the absorption data of SOA samples from Lambe et al. (2013) and Romonosky et al. (2016), real SOA absorbs $\sim 1-3$ orders of magnitude more than non-aromatic component surrogate species shown in Fig. 8 at $254 \mathrm{~nm}$. As discussed for multifunctional oxidation intermediates (with carbonyls and hydroxyls), SOA absorption enhancement may be largely due to transitions of charge transfer complexes formed between carbonyls and hydroxyls in multifunctional oxygenated SOA components (Phillips and Smith, 2014, 2015). These complexes between carbonyls and hydroxyls also have continua of states likely leading to ultrafast relaxation and hence low photolysis quantum yields. Charge transfer transitions have been extensively shown in measurements (Alif et al., 1991; Gao and Zepp, 1998; Johannessen and Miller, 2001; O'Sullivan et al., 2005; Zhang et al., 2006; Osburn et al., 2009; Sharpless and Blough, 2014) to have very low quantum yields in the condensed phase. Sharpless and Blough (2014) compiled quantum yields of various products of humic-like matter photolysis down to $280 \mathrm{~nm}$. No quantum yields except those of the product ${ }^{1} \mathrm{O}_{2}$, which is generally unimportant for OFRs (see Sect. 3.1.6), are higher than 0.01 . If the photolysis quantum yields of the SOA samples in Fig. 8 at $254 \mathrm{~nm}$ are no more than 0.01, no SOA samples will be photolyzed by $20 \%$ even at the highest OFR lamp setting, and photolysis of most SOA samples at $254 \mathrm{~nm}$ will be minor or negligible in OFRs. Thus, to our current knowledge, lack of solid information on quantum yields 

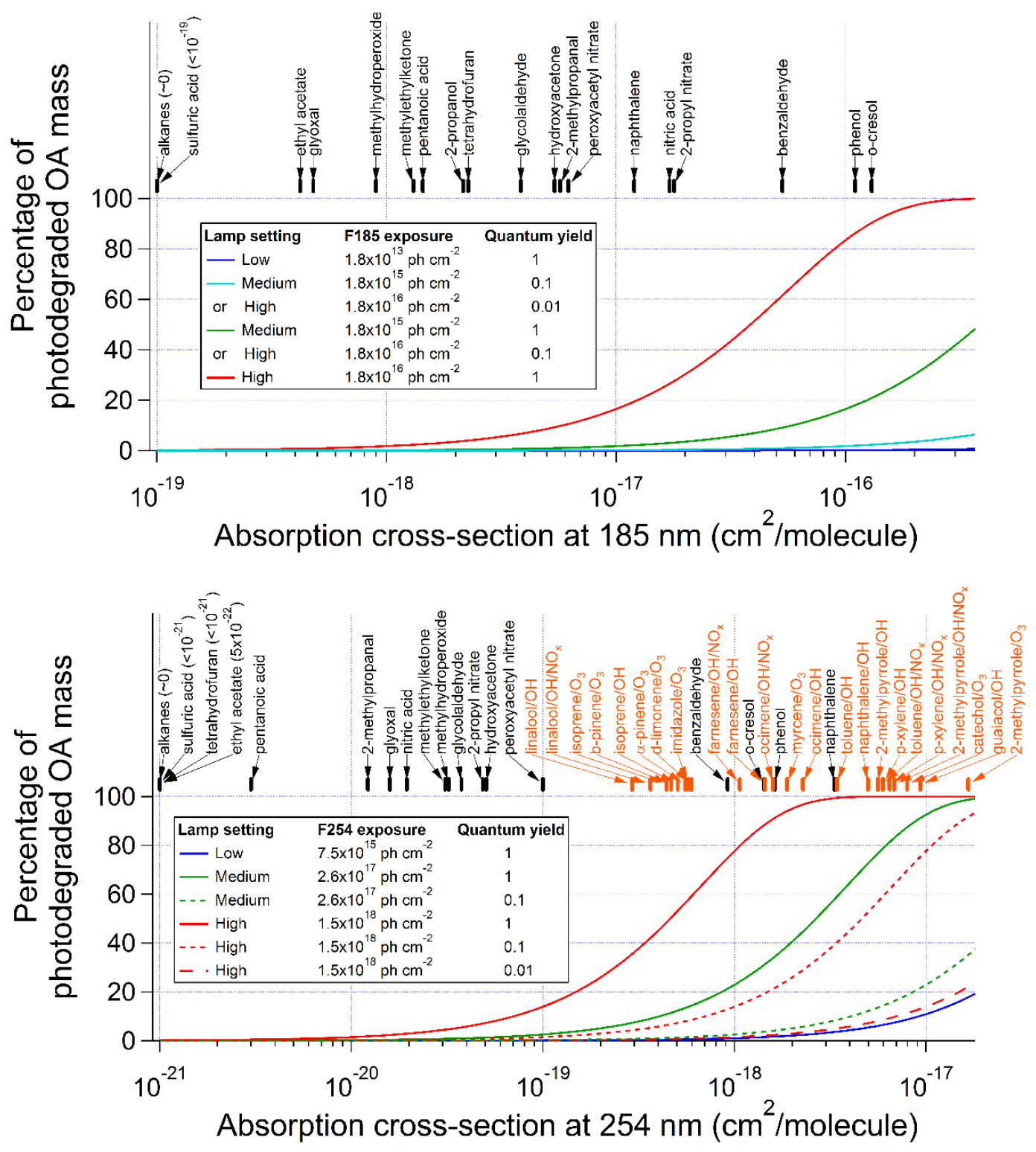

Figure 8. Percentage of SOA photodegradation at (upper panel) 185 and (lower panel) $254 \mathrm{~nm}$ at different UV levels as a function of absorption cross section under the assumptions of quantum yields of 1, 0.1, and 0.01. Absorption cross sections of some SOA component surrogates (black tag) and SOA samples (orange tag; calculated from data in Lambe et al., 2013, and Romonosky et al., 2016) are also shown.

of SOA components with multiple carbonyls and hydroxyls at $254 \mathrm{~nm}$ prevents a clear assessment of SOA photolysis in OFRs at the medium and high UV. Nonetheless, direct measurements are desirable for this issue and caution should still be exercised for OFR experiments at relatively high UV.

SOA photolysis at $185 \mathrm{~nm}$ may be lower compared to that at $254 \mathrm{~nm}$. SOA absorptivity data at $185 \mathrm{~nm}$ are not available. According to SOA mass-specific absorption cross-section (MAC) data between 250 and $300 \mathrm{~nm}$ in Romonosky et al. (2016), there is a linear relationship between the logarithm of MAC and wavelength for most SOA samples: MAC increases by a factor of $\sim 3$ per $50 \mathrm{~nm}$ decrease in wavelength.
We thus extrapolate this relationship to $185 \mathrm{~nm}$, where MAC is estimated to be $\sim 3.5$ times higher than that at $254 \mathrm{~nm}$. However, the UV flux at $185 \mathrm{~nm}$ in our OFR is $\sim 100$ times lower than at $254 \mathrm{~nm}$.

Based on the discussion above, the SOA photodegradation ratio of $\sim 30 \%$ in the non-OFR setup of Wong et al. (2015) may be explained. $\alpha$-Pinene-derived SOA has $\sim 20-50 \%$ weight fraction of peroxides (Docherty et al., 2005; Epstein et al., 2014), which may undergo photolysis in SOA to convert into carbonyls (and hydroxyls) (Epstein et al., 2014). We speculate that after the formation of carbonyls from peroxides, SOA materials cannot proceed significantly further 
with photolysis as discussed for charge transfer between carbonyl and hydroxyl above. In the experiments of Wong et al. (2015), as well as Epstein et al. (2014), effective photolysis rate constants/quantum yields decreased as SOA photolysis proceeded. Photolysis rates were substantially reduced after a $\sim 30 \%$ mass loss due to photolysis in the Wong et al. (2015) experiments. This mass loss ratio is consistent with the mass percentage of peroxides in $\alpha$-pinene-derived SOA. Again, we note that, according to the extrapolation from the results from Wong et al. (2015), the mass loss percentage expected in our OFR under the highest UV flux is $\sim 6 \%$ for $\alpha$-pinene-derived SOA. This value is much lower than that shown in Fig. 8 under the assumption of unity quantum yield $(\sim 40 \%)$ because of a substantially decreasing quantum yield in the real photolysis experiments. Therefore, in OFRs, even if (hydro)peroxides in SOA may be photolyzed in appreciable amounts, SOA mass is unlikely to be largely destroyed by photons in OFRs, as (hydro)peroxides may convert into carbonyls and hydroxyls, which may substantially lower subsequent photolysis quantum yields.

According to the discussion above, measurements of quantum yields and/or products of SOA photolysis are highly desirable, especially for the photolysis of SOA containing dominantly carbonyl and hydroxyl groups, as (hydro)peroxides, which are likely to form in OFRs, may convert into hydroxyls and carbonyls. With more data on quantum yields of SOA photolysis, a clearer strategy for including or excluding SOA photolysis in OFRs can be made.

Even though SOA photolysis can be significant in OFRs, it only proceeds to a much lesser extent compared to ambient SOA photolysis. We calculate the numbers of e-fold decay of SOA photolysis in OFR254-70 and the troposphere according to the effective ambient photolysis lifetime of SOA from Romonosky et al. (2016). Under the condition of $44 \%$ $\mathrm{RH}\left(\mathrm{H}_{2} \mathrm{O}=1.4 \%\right)$ and $\mathrm{OHR}_{\mathrm{ext}}=25 \mathrm{~s}^{-1}$ (typical of ambient conditions), SOA samples are estimated to undergo $\sim 0.01-$ 0.5 e-fold photolysis timescales (i.e., $\sim 1-35 \%$ OA photolyzed) in OFR254-70 at an equivalent photochemical age of 1 week under the upper limit assumption of unity quantum yields (Table S8). However, in the atmosphere, those samples may proceed with $10^{2}-10^{4}$ e-fold decays of photolysis (i.e., virtually complete destruction) at the same photochemical age, if ambient SOA photolysis quantum yields are assumed to be those of $\mathrm{H}_{2} \mathrm{O}_{2}$ (unity below $400 \mathrm{~nm}$ ). Even if the quantum yield of acetone (non-zero below $320 \mathrm{~nm}$; see Romonosky et al., 2016) is taken as a surrogate for SOA, most types of SOA would still be completely or nearly completely photolyzed under ambient conditions. These results demonstrate that ambient SOA photolysis is likely to be much more important than in OFRs. However, they also highlight the need for studies of ambient SOA photolysis quantum yields and photolytic aging, as ambient SOA is unlikely to be completely destroyed by photons within only 1 week. Either their quantum yields are much lower than used in this study or the photolabile groups are destroyed and leave behind others that are not (or less) photolabile during photolytic aging.

\subsection{Guidelines for OFR experimental design and operation}

It is necessary to avoid significant non-tropospheric chemistry in OFRs in order to more accurately simulate tropospheric aging. Only photolysis at 185 and $254 \mathrm{~nm}$ are important non-tropospheric pathways in OFRs and reactions with $\mathrm{O}$ atoms are generally unimportant. Ozonolysis is also a major VOC sink in the troposphere, and the desirability of including or excluding its effects depends on the goals of each experiment.

In the cases where the exclusion of VOC ozonolysis is desired, there is no dilemma for the experimental design, as the exclusion of both VOC ozonolysis and non-tropospheric VOC consumption requires similar conditions, i.e., safer conditions. As shown above, all examined field studies do not have significant non-tropospheric contribution to VOC fate, while some past laboratory and source studies do because of low $\mathrm{H}_{2} \mathrm{O}$ and/or very high $\mathrm{OHR}_{\text {ext }}$ in those experiments. It is possible to improve the latter experiments by increasing $\mathrm{H}_{2} \mathrm{O}$ and/or lowering $\mathrm{OHR}_{\text {ext }}$. In detail, source humidification and dilution can be feasible measures to increase $\mathrm{H}_{2} \mathrm{O}$ and decrease $\mathrm{OHR}_{\text {ext }}$, respectively. For example, increasing $\mathrm{RH}$ from 3 to $60 \%\left(\mathrm{H}_{2} \mathrm{O}\right.$ from $\sim 0.08$ to $\sim 1.6 \%$ ) lowers the percentage of non-tropospheric consumption of p-xylene in the Kang et al. (2011) mixture experiment from $\sim 20$ to $1.5 \%$. Humidifying the average condition of the BEACHON-RoMBAS (Palm et al., 2016) campaign from $\mathrm{H}_{2} \mathrm{O}=1.6 \%(\mathrm{RH}=63 \%)$ to $\mathrm{H}_{2} \mathrm{O}=2.3 \%$ $(\mathrm{RH}=92 \%)$ leads to a $\sim 50 \%$ decrease in non-tropospheric photolysis of $\alpha$-pinene (Table S4). Also, a 5-fold source dilution in FLAME-3 reduces the non-tropospheric fate of benzene from $>60$ to $\sim 15 \%$ (Table S4 and "Improved" cases in Fig. 7). Injecting less precursor is a simple way to keep a reasonably low $\mathrm{OHR}_{\mathrm{ext}}$ in laboratory studies. The comparison between the cases with high and low concentrations in the urban tunnel study (Tkacik et al., 2014) is a good example (Table S4 and Fig. 7). Note that when taking the measures above to limit non-tropospheric VOC fate, one generally reduces the contribution from all non-OH reactants. Increasing $\mathrm{H}_{2} \mathrm{O}$ and source dilution also significantly lower the relative importance of ozonolysis in the fate of $\alpha$-pinene in the Kang et al. (2011) mixture experiments and the FLAME-3 study (Table S4 and Fig. 7). Although increasing UV may increase $\mathrm{OH}$ production, $\mathrm{OH}$ reactant destruction, and hence the relative contribution of $\mathrm{OH}$ to $\mathrm{VOC}$ fate in some cases, one has to be cautious when taking this measure to reduce effective $\mathrm{OHR}_{\text {ext }}$, as high UV may cause non-tropospheric photolysis of SOA.

In laboratory experiments, running OFRs under safer conditions ensures a minor contribution of non-tropospheric photolysis, based on the current knowledge of oxidation in- 
termediate photolysis (Fig. 2). This also reduces the relative contribution of ozonolysis to VOC fate. However, when more information becomes available about photolysis quantum yields of oxidation intermediates (vs. the upper limits assumed here), there may be additional flexibility to include ozonolysis while excluding non-tropospheric VOC consumption. As the precursor composition is usually relatively simple in laboratory experiments, it is sufficient to ensure the insignificance of non-tropospheric consumption of only the precursor(s) and possible intermediates (usually oxygenated species), rather than for a large variety of VOC precursors and intermediates. For example, in the case of quantum yields significantly lower than used in the present work, we may perform OFR254-70 experiments with a large amount of biogenics at medium $\mathrm{H}_{2} \mathrm{O}$ and UV. In this case, a tropospheric $\mathrm{O}_{3 \exp } / \mathrm{OH}_{\exp }$ ratio can be obtained without major side effects, because the fractional contribution of photolysis of possible intermediates is still minor due to low quantum yields. However, OFR experiments with some anthropogenic VOCs, such as alkanes, can just be conducted at high $\mathrm{H}_{2} \mathrm{O}$ and low $\mathrm{OHR}_{\text {ext }}$ to avoid the contribution of all non-OH reactants, since ozonolysis of alkanes is negligible even at a tropospheric $\mathrm{O}_{3 \exp } / \mathrm{OH}_{\text {exp }}$.

OFR experiments can be simply conducted under safer conditions to avoid non-tropospheric VOC fate, while riskier conditions can lead to significant non-tropospheric VOC fate, depending on the species under study. The conditions in between, i.e., "transition" conditions, are explicitly discussed above. However, one may want to be able to more quantitatively estimate the relative importance of non-OH reactants under different conditions so that a more detailed experimental planning becomes possible that simultaneously ensures insignificant non-tropospheric VOC fate and specific experimental goals. For this purpose, we provide a series of estimation equations for non-OH reactant exposures (Sect. S3, Table S9, and Fig. S6, as well as Excel file). With these equations, the relative contribution of non-OH reactants under all conditions explored in this study can be easily estimated. In OFR studies where a different OFR design is adopted and/or chemistry beyond the approximations in our model is involved, a new model may need to be established, which can be done in similar manner as Peng et al. (2015), to obtain the relative importance of non-OH VOC fate and then perform experimental design.

\section{Conclusions}

We used a kinetic model to investigate non- $\mathrm{OH}$ contribution (from 185 and $254 \mathrm{~nm}$ photons, $\mathrm{O}\left({ }^{1} \mathrm{D}\right), \mathrm{O}\left({ }^{3} \mathrm{P}\right)$, and $\mathrm{O}_{3}$ ) to VOC destruction, as well as to SOA photolysis at 185 and $254 \mathrm{~nm}$ in OFRs. We assessed the relative significance of the VOC consumption by non- $\mathrm{OH}$ reactants to that by $\mathrm{OH}$ in OFRs and the troposphere. The only non-tropospheric reaction that can play a major role under OFR conditions is photolysis, especially at $254 \mathrm{~nm}$. The relative importance of photolysis is largest under riskier OFR conditions where $\mathrm{OH}$ is low due to low $\mathrm{H}_{2} \mathrm{O}$ and/or high $\mathrm{OHR}_{\text {ext. }}$. Due to lack of quantum yield data, we estimated upper limits of the relative importance of photolysis for the few most susceptible oxidation intermediates, which are comparable to those from aromatic precursors. Reactions of $\mathrm{O}$ atoms are not competitive and are actually of lower relative importance (vs. $\mathrm{OH}$ ) in OFRs than in the troposphere. VOC ozonolysis is much less important than in the troposphere under typical OFR conditions and of similar importance under riskier OFR conditions. Photolysis of SOA in OFRs could be significant at medium and high UV, but only if corresponding quantum yields are high. If SOA photolysis quantum yields are of the order of 0.01 or lower, as measured for many humic-like substances (Sharpless and Blough, 2014), SOA photolysis in OFRs may be minor or negligible under most conditions. Although the reaction fates may be different, numbers of e-fold decays of photolysis for a given $\mathrm{OH}_{\text {exp }}$ are at least an order of magnitude lower in the OFRs compared to the troposphere.

We examined some past field, laboratory, and source studies using OFRs. In the field studies of aged urban and forest ambient air, non-OH VOC fate was not important because of relatively high $\mathrm{H}_{2} \mathrm{O}$ and moderate $\mathrm{OHR}_{\text {ext }}$. However, some laboratory and source studies were conducted at low $\mathrm{H}_{2} \mathrm{O}$ and/or high $\mathrm{OHR}_{\text {ext }}$ and have significant non-tropospheric VOC consumption. Humidification and/or dilution are recommended in these cases to reduce the importance of nontropospheric reactants. We proposed different approaches to avoid non-OH VOC consumption, as well as strategies to employ insignificant non-tropospheric photolysis and significant tropospheric ozonolysis simultaneously in laboratory experiments. Our work has implications for the interpretation of past OFR studies and should be useful for designing and conducting future OFR experiments for atmospheric research, as well as in related applied fields.

The need for systematic measurements of photolysis quantum yields, for both VOC and SOA, and both at actinic wavelengths and at 185 and $254 \mathrm{~nm}$, was highlighted in this study. When quantum yield data become available, photolysis of oxidation precursors, oxidation intermediates, and SOA in OFRs can be much better quantified, its relative importance compared to $\mathrm{OH}$ oxidation, ambient photolysis, etc. can be better evaluated, and experimental planning might then be able to be less conservative and have more freedom to avoid non-tropospheric photolysis and realize specific experimental objective(s).

\section{The Supplement related to this article is available online at doi:10.5194/acp-16-4283-2016-supplement.}


Acknowledgements. We thank Veronica Vaida, Paul Ziemann, Andrew Lambe, and the PAM user community for useful discussions, Andrew Lambe and Daniel Tkacik for providing some OFR experimental data and the reviewers for their useful comments for improving the manuscript. This research was partially supported by CARB 11-305, DOE (BER/ASR) DE-SC0011105, NSF AGS-1243354 \& AGS-1360834, and NASA NNX15AT96G. Amber M. Ortega acknowledges fellowships from DOE and CU Graduate School. Rui Li and Brett B. Palm acknowledge CIRES Fellowships. Brett B. Palm is grateful for a Fellowship from US EPA STAR (FP-91761701-0). Resources supporting this work were provided by the NASA High-End Computing (HEC) Program through the NASA Center for Climate Simulation (NCCS) at Goddard Space Flight Center.

Edited by: J. H. Seinfeld

\section{References}

Aimanant, S. and Ziemann, P. J.: Chemical Mechanisms of Aging of Aerosol Formed from the Reaction of n-Pentadecane with $\mathrm{OH}$ Radicals in the Presence of $\mathrm{NO}_{x}$, Aerosol Sci. Technol., 47, 979990, doi:10.1080/02786826.2013.804621, 2013.

Alif, A., Pilichowski, J., and Boule, P.: photochemistry and environment XIII phototransformation of 2-nitrophenol in aqueous solution, J. Photoch. Photobio. A, 59, 209-219, doi:10.1016/10106030(91)87009-K, 1991.

Ammann, M., Cox, R. A., Crowley, J. N., Jenkin, M. E., Mellouki, A., Rossi, M. J., Troe, J., Wallington, T. J., Cox, B., Atkinson, R., Baulch, D. L., and Kerr, J. A.: IUPAC Task Group on Atmospheric Chemical Kinetic Data Evaluation, available at: http://iupac.pole-ether.fr/\#, last access: November 2015.

Atkinson, R. and Arey, J.: Atmospheric degradation of volatile organic compounds, Chem. Rev., 103, 4605-4638, doi:10.1021/cr0206420, 2003.

Bahreini, R., Middlebrook, A. M., Brock, C. A., de Gouw, J. A., McKeen, S. A., Williams, L. R., Daumit, K. E., Lambe, A. T., Massoli, P., Canagaratna, M. R., Ahmadov, R., Carrasquillo, A. J., Cross, E. S., Ervens, B., Holloway, J. S., Hunter, J. F., Onasch, T. B., Pollack, I. B., Roberts, J. M., Ryerson, T. B., Warneke, C., Davidovits, P., Worsnop, D. R., and Kroll, J. H.: Mass spectral analysis of organic aerosol formed downwind of the Deepwater Horizon oil spill: field studies and laboratory confirmations, Environ. Sci. Technol., 46, 8025-8034, doi:10.1021/es301691k, 2012.

Baker, L. A., Horbury, M. D., Greenough, S. E., Coulter, P. M., Karsili, T. N. V., Roberts, G. M., Orr-Ewing, A. J., Ashfold, M. N. R., and Stavros, V. G.: Probing the Ultrafast Energy Dissipation Mechanism of the Sunscreen Oxybenzone after UVA Irradiation, J. Phys. Chem. Lett., 6, 1363-1368, doi:10.1021/acs.jpclett.5b00417, 2015.

Baulch, D. L., Cobos, C. J., Cox, R. A., Esser, C., Frank, P., Just, T., Kerr, J. A., Pilling, M. J., Troe, J., Walker, R. W., and Warnatz, J.: Evaluated Kinetic Data for Combustion Modelling, J. Phys. Chem. Ref. Data, 21, 411, doi:10.1063/1.555908, 1992.

Baulch, D. L., Bowman, C. T., Cobos, C. J., Cox, R. A., Just, T., Kerr, J. A., Pilling, M. J., Stocker, D., Troe, J., Tsang, W., Walker, R. W., and Warnatz, J.: Evaluated kinetic data for combustion modeling, Supplement II, J. Phys. Chem. Ref. Data, 34, 7571397, doi:10.1063/1.1748524, 2005.

Beddard, G. S., Fleming, G. R., Gijzeman, O. L. J., and Porter, G.: Vibrational Energy Dependence of Radiationless Conversion in Aromatic Vapours, P. Roy. Soc. A-Math. Phy., 340, 519-533, doi:10.1098/rspa.1974.0168, 1974.

Borbon, A., Gilman, J. B., Kuster, W. C., Grand, N., Chevaillier, S., Colomb, A., Dolgorouky, C., Gros, V., Lopez, M., Sarda-Esteve, R., Holloway, J., Stutz, J., Petetin, H., McKeen, S., Beekmann, M., Warneke, C., Parrish, D. D., and De Gouw, J. A.: Emission ratios of anthropogenic volatile organic compounds in northern mid-latitude megacities: Observations versus emission inventories in Los Angeles and Paris, J. Geophys. Res.-Atmos., 118, 2041-2057, doi:10.1002/jgrd.50059, 2013.

Bouzidi, H., Laversin, H., Tomas, A., Coddeville, P., Fittschen, C., El Dib, G., Roth, E., and Chakir, A.: Reactivity of 3-hydroxy-3methyl-2-butanone: Photolysis and $\mathrm{OH}$ reaction kinetics, Atmos. Environ., 98, 540-548, doi:10.1016/j.atmosenv.2014.09.033, 2014.

Bouzidi, H., Aslan, L., El Dib, G., Coddeville, P., Fittschen, C., and Tomas, A.: Investigation of the Gas-Phase Photolysis and Temperature-Dependent $\mathrm{OH}$ Reaction Kinetics of 4Hydroxy-2-butanone, Environ. Sci. Technol., 49, 12178-12186, doi:10.1021/acs.est.5b02721, 2015.

Calvert, J. G., Atkinson, R., Becker, K. H., Kamens, R. M., Seinfeld, J. H., Wallington, T. H., and Yarwood, G.: The Mechanisms of Atmospheric Oxidation of the Aromatic Hydrocarbons, Oxford University Press, USA, available at: https://books.google.com/ books?id=P0basaLrxDMC (last access: November 2015), 2002.

Carlton, A. G., Wiedinmyer, C., and Kroll, J. H.: A review of Secondary Organic Aerosol (SOA) formation from isoprene, Atmos. Chem. Phys., 9, 4987-5005, doi:10.5194/acp-9-4987-2009, 2009.

Carter, W. P. L., Cocker, D. R., Fitz, D. R., Malkina, I. L., Bumiller, K., Sauer, C. G., Pisano, J. T., Bufalino, C., and Song, C.: A new environmental chamber for evaluation of gas-phase chemical mechanisms and secondary aerosol formation, Atmos. Environ., 39, 7768-7788, doi:10.1016/j.atmosenv.2005.08.040, 2005.

Cocker, D. R., Flagan, R. C., and Seinfeld, J. H.: State-of-the-Art Chamber Facility for Studying Atmospheric Aerosol Chemistry, Environ. Sci. Technol., 35, 2594-2601, doi:10.1021/es0019169, 2001.

Cours, T., Canneaux, S., and Bohr, F.: Features of the potential energy surface for the reaction of $\mathrm{HO}_{2}$ radical with acetone, Int. J. Quantum Chem., 107, 1344-1354, doi:10.1002/qua.21269, 2007.

Cubison, M. J., Ortega, A. M., Hayes, P. L., Farmer, D. K., Day, D., Lechner, M. J., Brune, W. H., Apel, E., Diskin, G. S., Fisher, J. A., Fuelberg, H. E., Hecobian, A., Knapp, D. J., Mikoviny, T., Riemer, D., Sachse, G. W., Sessions, W., Weber, R. J., Weinheimer, A. J., Wisthaler, A., and Jimenez, J. L.: Effects of aging on organic aerosol from open biomass burning smoke in aircraft and laboratory studies, Atmos. Chem. Phys., 11, 12049-12064, doi:10.5194/acp-11-12049-2011, 2011.

Damschen, D. E., Merritt, C. D., Perry, D. L., Scott, G. W., and Talley, L. D.: Intersystem Crossing Kinetics, J. Phys. Chem., 82, 2268-2272, doi:10.1021/j100510a002, 1978.

da Silva, G. and Bozzelli, J. W.: Role of the $\alpha$-hydroxyethylperoxy radical in the reactions of acetaldehyde and vinyl al- 
cohol with $\mathrm{HO}_{2}$, Chem. Phys. Lett., 483, 25-29, doi:10.1016/j.cplett.2009.10.045, 2009.

Docherty, K. S., Wu, W., Lim, Y. B., and Ziemann, P. J.: Contributions of Organic Peroxides to Secondary Aerosol Formed from Reactions of Monoterpenes with $\mathrm{O}_{3}$, Environ. Sci. Technol., 39, 4049-4059, doi:10.1021/es050228s, 2005.

Dzepina, K., Volkamer, R. M., Madronich, S., Tulet, P., Ulbrich, I. M., Zhang, Q., Cappa, C. D., Ziemann, P. J., and Jimenez, J. L.: Evaluation of recently-proposed secondary organic aerosol models for a case study in Mexico City, Atmos. Chem. Phys., 9, 5681-5709, doi:10.5194/acp-9-5681-2009, 2009.

Eisenberg, W. C., Taylor, K., and Murray, R. W.: Gas-Phase Kinetics of the Reaction of Singlet Oxygen with Olefins at Atmospheric Pressure, J. Phys. Chem., 90, 1945-1948, doi:10.1021/j100400a041, 1986.

Epstein, S. A., Shemesh, D., Tran, V. T., Nizkorodov, S. A., and Gerber, R. B.: Absorption Spectra and Photolysis of Methyl Peroxide in Liquid and Frozen Water, J. Phys. Chem. A, 116, 6068-6077, doi:10.1021/jp211304v, 2012.

Epstein, S. A., Blair, S. L., and Nizkorodov, S. A.: Direct Photolysis of $\alpha$-Pinene Ozonolysis Secondary Organic Aerosol: Effect on Particle Mass and Peroxide Content, Environ. Sci. Technol., 48, 11251-11258, doi:10.1021/es502350u, 2014.

Evans, R. C., Douglas, P., and Burrow, H. D. (Eds.): Applied Photochemistry, Springer Netherlands, Dordrecht, the Netherlands, 2013.

Fang, W. H. and Phillips, D. L.: The crucial role of the $\mathrm{S} 1 / \mathrm{T} 2 / \mathrm{T} 1$ intersection in the relaxation dynamics of aromatic carbonyl compounds upon $n>\pi^{*}$ excitation, Chem. Phys. Chem., 3, 889-892, doi:10.1002/1439-7641(20021018)3:10<889::AIDCPHC889>3.0.CO;2-U, 2002.

Foster, R.: Organic Charge-Transfer Complexes, Academic Press, New York, USA, 1969.

Francisco, J. S. and Eisfeld, W.: Atmospheric Oxidation Mechanism of Hydroxymethyl Hydroperoxide, J. Phys. Chem. A, 113, 75937600, doi:10.1021/jp901735z, 2009.

Gäb, S., Hellpointner, E., Turner, W. V., and Koŕte, F.: Hydroxymethyl hydroperoxide and bis(hydroxymethyl) peroxide from gas-phase ozonolysis of naturally occurring alkenes, Nature, 316 , 535-536, doi:10.1038/316535a0, 1985.

Gao, H. and Zepp, R. G.: Factors Influencing Photoreactions of Dissolved Organic Matter in a Coastal River of the Southeastern United States, Environ. Sci. Technol., 32, 2940-2946, doi:10.1021/es9803660, 1998.

George, I. J., Vlasenko, A., Slowik, J. G., Broekhuizen, K., and Abbatt, J. P. D.: Heterogeneous oxidation of saturated organic aerosols by hydroxyl radicals: uptake kinetics, condensed-phase products, and particle size change, Atmos. Chem. Phys., 7, 41874201, doi:10.5194/acp-7-4187-2007, 2007.

Gierczak, T. and Ravishankara, A. R.: Does the $\mathrm{HO}_{2}$ radical react with ketones?, Int. J. Chem. Kinet., 32, 573-580, doi:10.1002/1097-4601(2000)32:9<573::AID-KIN7>3.0.CO;2$\mathrm{V}, 2000$.

Goldstein, S., Aschengrau, D., Diamant, Y., and Rabani, J.: Photolysis of Aqueous $\mathrm{H}_{2} \mathrm{O}_{2}$ ?: Quantum Yield and Applications for Polychromatic UV Actinometry in Photoreactors, Environ. Sci. Technol., 41, 7486-7490, doi:10.1021/es071379t, 2007.

Hallquist, M., Wenger, J. C., Baltensperger, U., Rudich, Y., Simpson, D., Claeys, M., Dommen, J., Donahue, N. M., George,
C., Goldstein, A. H., Hamilton, J. F., Herrmann, H., Hoffmann, T., Iinuma, Y., Jang, M., Jenkin, M. E., Jimenez, J. L., Kiendler-Scharr, A., Maenhaut, W., McFiggans, G., Mentel, Th. F., Monod, A., Prévôt, A. S. H., Seinfeld, J. H., Surratt, J. D., Szmigielski, R., and Wildt, J.: The formation, properties and impact of secondary organic aerosol: current and emerging issues, Atmos. Chem. Phys., 9, 5155-5236, doi:10.5194/acp-9-51552009, 2009.

Hayes, P. L., Carlton, A. G., Baker, K. R., Ahmadov, R., Washenfelder, R. A., Alvarez, S., Rappenglück, B., Gilman, J. B., Kuster, W. C., de Gouw, J. A., Zotter, P., Prévôt, A. S. H., Szidat, S., Kleindienst, T. E., Offenberg, J. H., Ma, P. K., and Jimenez, J. L.: Modeling the formation and aging of secondary organic aerosols in Los Angeles during CalNex 2010, Atmos. Chem. Phys., 15, 5773-5801, doi:10.5194/acp-15-5773-2015, 2015.

Hodzic, A., Madronich, S., Kasibhatla, P. S., Tyndall, G., Aumont, B., Jimenez, J. L., Lee-Taylor, J., and Orlando, J.: Organic photolysis reactions in tropospheric aerosols: effect on secondary organic aerosol formation and lifetime, Atmos. Chem. Phys., 15, 9253-9269, doi:10.5194/acp-15-9253-2015, 2015.

Hoffmann, T., Odum, J. R., Bowman, F., Collins, D., Klockow, D., Flagan, R. C., and Seinfeld., J. H.: Formation of Organic Aerosols from the Oxidation of Biogenic Hydrocarbons, J. Atmos. Chem., 26, 189-222, doi:10.1023/A:1005734301837, 1997.

Hu, W. W., Campuzano-Jost, P., Palm, B. B., Day, D. A., Ortega, A. M., Hayes, P. L., Krechmer, J. E., Chen, Q., Kuwata, M., Liu, Y. J., de Sá, S. S., McKinney, K., Martin, S. T., Hu, M., Budisulistiorini, S. H., Riva, M., Surratt, J. D., St. Clair, J. M., Isaacman-Van Wertz, G., Yee, L. D., Goldstein, A. H., Carbone, S., Brito, J., Artaxo, P., de Gouw, J. A., Koss, A., Wisthaler, A., Mikoviny, T., Karl, T., Kaser, L., Jud, W., Hansel, A., Docherty, K. S., Alexander, M. L., Robinson, N. H., Coe, H., Allan, J. D., Canagaratna, M. R., Paulot, F., and Jimenez, J. L.: Characterization of a real-time tracer for isoprene epoxydiols-derived secondary organic aerosol (IEPOX-SOA) from aerosol mass spectrometer measurements, Atmos. Chem. Phys., 15, 11807-11833, doi:10.5194/acp-15-11807-2015, 2015.

Huie, R. E. and Herron, J. T.: Kinetics of the reactions of singlet molecular oxygen $\left(\mathrm{O}_{2}{ }^{1} \Delta_{\mathrm{g}}\right)$ with organic compounds in the gas phase, Int. J. Chem. Kinet., 5, 197-211, doi:10.1002/kin.550050204, 1973.

Jathar, S. H., Cappa, C. D., Wexler, A. S., Seinfeld, J. H., and Kleeman, M. J.: Multi-generational oxidation model to simulate secondary organic aerosol in a 3-D air quality model, Geosci. Model Dev., 8, 2553-2567, doi:10.5194/gmd-8-2553-2015, 2015.

Johannessen, S. C. and Miller, W. L.: Quantum yield for the photochemical production of dissolved inorganic carbon in seawater, Mar. Chem., 76, 271-283, doi:10.1016/S0304-4203(01)00067-6, 2001.

Johnson, M. S., Nilsson, E. J. K., Svensson, E. A., and Langer, S.: Gas-Phase Advanced Oxidation for Effective, Efficient in Situ Control of Pollution, Environ. Sci. Technol., 48, 8768-8776, doi:10.1021/es5012687, 2014.

Kang, E., Root, M. J., Toohey, D. W., and Brune, W. H.: Introducing the concept of Potential Aerosol Mass (PAM), Atmos. Chem. Phys., 7, 5727-5744, doi:10.5194/acp-7-5727-2007, 2007.

Kang, E., Toohey, D. W., and Brune, W. H.: Dependence of SOA oxidation on organic aerosol mass concentration and $\mathrm{OH}$ expo- 
sure: experimental PAM chamber studies, Atmos. Chem. Phys., 11, 1837-1852, doi:10.5194/acp-11-1837-2011, 2011.

Keller-Rudek, H., Moortgat, G. K., Sander, R., and Sörensen, R.: The MPI-Mainz UV/VIS Spectral Atlas of Gaseous Molecules of Atmospheric Interest, available at: www.uv-vis-spectral-atlas-mainz.org, last access: November 2015.

Klems, J. P., Lippa, K. A., and McGivern, W. S.: Quantitative Evidence for Organic Peroxy Radical Photochemistry at $254 \mathrm{~nm}$, J. Phys. Chem. A, 119, 344-351, doi:10.1021/jp509165x, 2015.

Kumar, M. and Francisco, J. S.: Red-Light-Induced Decomposition of an Organic Peroxy Radical: A New Source of the $\mathrm{HO}_{2}$ Radical, Angew. Chemie Int. Ed., 54, 15711-15714, doi:10.1002/anie.201509311, 2015.

Kwok, E. and Atkinson, R.: Estimation of hydroxyl radical reaction rate constants for gas-phase organic compounds using a structure-reactivity relationship: An update, Atmos. Environ., 29, 1685-1695, doi:10.1016/1352-2310(95)00069-B, 1995.

Lambe, A. T., Ahern, A. T., Williams, L. R., Slowik, J. G., Wong, J. P. S., Abbatt, J. P. D., Brune, W. H., Ng, N. L., Wright, J. P., Croasdale, D. R., Worsnop, D. R., Davidovits, P., and Onasch, T. B.: Characterization of aerosol photooxidation flow reactors: heterogeneous oxidation, secondary organic aerosol formation and cloud condensation nuclei activity measurements, Atmos. Meas. Tech., 4, 445-461, doi:10.5194/amt-4-445-2011, $2011 \mathrm{a}$.

Lambe, A. T., Onasch, T. B., Massoli, P., Croasdale, D. R., Wright, J. P., Ahern, A. T., Williams, L. R., Worsnop, D. R., Brune, W. H., and Davidovits, P.: Laboratory studies of the chemical composition and cloud condensation nuclei $(\mathrm{CCN})$ activity of secondary organic aerosol (SOA) and oxidized primary organic aerosol (OPOA), Atmos. Chem. Phys., 11, 8913-8928, doi:10.5194/acp11-8913-2011, $2011 \mathrm{~b}$.

Lambe, A. T., Onasch, T. B., Croasdale, D. R., Wright, J. P., Martin, A. T., Franklin, J. P., Massoli, P., Kroll, J. H., Canagaratna, M. R., Brune, W. H., Worsnop, D. R., and Davidovits, P.: Transitions from Functionalization to Fragmentation Reactions of Laboratory Secondary Organic Aerosol (SOA) Generated from the OH Oxidation of Alkane Precursors, Environ. Sci. Technol., 46, 5430-5437, doi:10.1021/es300274t, 2012.

Lambe, A. T., Cappa, C. D., Massoli, P., Onasch, T. B., Forestieri, S. D., Martin, A. T., Cummings, M. J., Croasdale, D. R., Brune, W. H., Worsnop, D. R., and Davidovits, P.: Relationship between Oxidation Level and Optical Properties of Secondary Organic Aerosol, Environ. Sci. Technol., 47, 6349-6357, doi:10.1021/es401043j, 2013.

Lambe, A. T., Chhabra, P. S., Onasch, T. B., Brune, W. H., Hunter, J. F., Kroll, J. H., Cummings, M. J., Brogan, J. F., Parmar, Y., Worsnop, D. R., Kolb, C. E., and Davidovits, P.: Effect of oxidant concentration, exposure time, and seed particles on secondary organic aerosol chemical composition and yield, Atmos. Chem. Phys., 15, 3063-3075, doi:10.5194/acp-15-3063-2015, 2015.

Laue, T. and Plagens, A.: Named Organic Reactions, 2nd ed., John Wiley \& Sons, Chichester, England, New York, USA, available at: http://www.wiley.com/WileyCDA/WileyTitle/ productCd-047001041X.html (last access: November 2015), 2005.

Levy II, H.: Normal atmosphere: large radical and formaldehyde concentrations predicted., Science, 173, 141-143, doi:10.1126/science.173.3992.141, 1971.
Li, R., Palm, B. B., Borbon, A., Graus, M., Warneke, C., Ortega, A. M., Day, D. A., Brune, W. H., Jimenez, J. L., and de Gouw, J. A.: Laboratory Studies on Secondary Organic Aerosol Formation from Crude Oil Vapors, Environ. Sci. Technol., 47, 1256612574, doi:10.1021/es402265y, 2013.

Li, R., Palm, B. B., Ortega, A. M., Hu, W., Peng, Z., Day, D. A., Knote, C., Brune, W. H., de Gouw, J., and Jimenez, J. L.: Modeling the radical chemistry in an Oxidation Flow Reactor (OFR): radical formation and recycling, sensitivities, and $\mathrm{OH}$ exposure estimation equation, J. Phys. Chem. A, 119, 4418-4432, doi:10.1021/jp509534k, 2015.

Liu, P., Zhang, Y., and Martin, S. T.: Complex refractive indices of thin films of secondary organic materials by spectroscopic ellipsometry from 220 to $1200 \mathrm{~nm}$, Environ. Sci. Technol., 47, 13594-13601, doi:10.1021/es403411e, 2013.

Liu, P. F., Abdelmalki, N., Hung, H.-M., Wang, Y., Brune, W. H., and Martin, S. T.: Ultraviolet and visible complex refractive indices of secondary organic material produced by photooxidation of the aromatic compounds toluene and $m$-xylene, Atmos. Chem. Phys., 15, 1435-1446, doi:10.5194/acp-15-1435-2015, 2015.

Mao, J., Ren, X., Brune, W. H., Olson, J. R., Crawford, J. H., Fried, A., Huey, L. G., Cohen, R. C., Heikes, B., Singh, H. B., Blake, D. R., Sachse, G. W., Diskin, G. S., Hall, S. R., and Shetter, R. E.: Airborne measurement of $\mathrm{OH}$ reactivity during INTEX-B, Atmos. Chem. Phys., 9, 163-173, doi:10.5194/acp-9-163-2009, 2009.

Massoli, P., Lambe, A. T., Ahern, A. T., Williams, L. R., Ehn, M., Mikkilä, J., Canagaratna, M. R., Brune, W. H., Onasch, T. B., Jayne, J. T., Petäjä, T., Kulmala, M., Laaksonen, A., Kolb, C. E., Davidovits, P., and Worsnop, D. R.: Relationship between aerosol oxidation level and hygroscopic properties of laboratory generated secondary organic aerosol (SOA) particles, Geophys. Res. Lett., 37, L24801, doi:10.1029/2010GL045258, 2010.

Matsunaga, A. and Ziemann, P. J.: Gas-Wall Partitioning of Organic Compounds in a Teflon Film Chamber and Potential Effects on Reaction Product and Aerosol Yield Measurements, Aerosol Sci. Technol., 44, 881-892, doi:10.1080/02786826.2010.501044, 2010.

Messaadia, L., El Dib, G., Ferhati, A., and Chakir, A.: UV-visible spectra and gas-phase rate coefficients for the reaction of 2,3pentanedione and 2,4-pentanedione with $\mathrm{OH}$ radicals, Chem. Phys. Lett., 626, 73-79, doi:10.1016/j.cplett.2015.02.032, 2015.

Monks, P. S.: Gas-phase radical chemistry in the troposphere, Chem. Soc. Rev., 34, 376-395, doi:10.1039/b307982c, 2005.

Nakashima, N.: Laser photolysis of benzene. V. Formation of hot benzene, J. Chem. Phys., 77, 6040, doi:10.1063/1.443847, 1982.

Nakashima, N. and Yoshihara, K.: Laser flash photolysis of benzene. VIII. Formation of hot benzene from the $\mathrm{S}_{2}$ state and its collisional deactivation, J. Chem. Phys., 79, 2727-2735, doi:10.1063/1.446176, 1983.

Nguyen, T. B., Crounse, J. D., Schwantes, R. H., Teng, A. P., Bates, K. H., Zhang, X., St. Clair, J. M., Brune, W. H., Tyndall, G. S., Keutsch, F. N., Seinfeld, J. H., and Wennberg, P. O.: Overview of the Focused Isoprene eXperiment at the California Institute of Technology (FIXCIT): mechanistic chamber studies on the oxidation of biogenic compounds, Atmos. Chem. Phys., 14, 1353113549, doi:10.5194/acp-14-13531-2014, 2014.

Odum, J. R., Hoffmann, T., Bowman, F., Collins, D., Flagan, R. C., and Seinfeld, J. H.: Gas particle partitioning and secondary 
organic aerosol yields, Environ. Sci. Technol., 30, 2580-2585, doi:10.1021/es950943+, 1996.

Ono, R., Nakagawa, Y., Tokumitsu, Y., Matsumoto, H., and Oda, T.: Effect of humidity on the production of ozone and other radicals by low-pressure mercury lamps, J. Photoch. Photobio. A, 274, 13-19, doi:10.1016/j.jphotochem.2013.09.012, 2014.

Ortega, A. M., Day, D. A., Cubison, M. J., Brune, W. H., Bon, D., de Gouw, J. A., and Jimenez, J. L.: Secondary organic aerosol formation and primary organic aerosol oxidation from biomass-burning smoke in a flow reactor during FLAME-3, Atmos. Chem. Phys., 13, 11551-11571, doi:10.5194/acp-1311551-2013, 2013.

Ortega, A. M., Hayes, P. L., Peng, Z., Palm, B. B., Hu, W., Day, D. A., Li, R., Cubison, M. J., Brune, W. H., Graus, M., Warneke, C., Gilman, J. B., Kuster, W. C., de Gouw, J. A., and Jimenez, J. L.: Real-time measurements of secondary organic aerosol formation and aging from ambient air in an oxidation flow reactor in the Los Angeles area, Atmos. Chem. Phys. Discuss., 15, 21907-21958, doi:10.5194/acpd-15-21907-2015, 2015.

Osburn, C. L., Retamal, L., and Vincent, W. F.: Photoreactivity of chromophoric dissolved organic matter transported by the Mackenzie River to the Beaufort Sea, Mar. Chem., 115, 10-20, doi:10.1016/j.marchem.2009.05.003, 2009.

O'Sullivan, D. W., Neale, P. J., Coffin, R. B., Boyd, T. J., and Osburn, C. L.: Photochemical production of hydrogen peroxide and methylhydroperoxide in coastal waters, Mar. Chem., 97, 14-33, doi:10.1016/j.marchem.2005.04.003, 2005.

Palm, B. B., Campuzano-Jost, P., Ortega, A. M., Day, D. A., Kaser, L., Jud, W., Karl, T., Hansel, A., Hunter, J. F., Cross, E. S., Kroll, J. H., Peng, Z., Brune, W. H., and Jimenez, J. L.: In situ secondary organic aerosol formation from ambient pine forest air using an oxidation flow reactor, Atmos. Chem. Phys., 16, $2943-$ 2970, doi:10.5194/acp-16-2943-2016, 2016.

Peng, Z., Day, D. A., Stark, H., Li, R., Lee-Taylor, J., Palm, B. B., Brune, W. H., and Jimenez, J. L.: $\mathrm{HO}_{x}$ radical chemistry in oxidation flow reactors with low-pressure mercury lamps systematically examined by modeling, Atmos. Meas. Tech., 8, 4863-4890, doi:10.5194/amt-8-4863-2015, 2015.

Phillips, S. M. and Smith, G. D.: Light Absorption by Charge Transfer Complexes in Brown Carbon Aerosols, Environ. Sci. Technol. Lett., 1, 382-386, doi:10.1021/ez500263j, 2014.

Phillips, S. M. and Smith, G. D.: Further Evidence for Charge Transfer Complexes in Brown Carbon Aerosols from ExcitationEmission Matrix Fluorescence Spectroscopy, J. Phys. Chem. A, 119, 4545-4551, doi:10.1021/jp510709e, 2015.

Pitts, J. N. and Finlayson, B. J.: Mechanismen der photochemischen Luftverschmutzung, Angew. Chemie, 87, 18-33, doi:10.1002/ange.19750870103, 1975.

Platt, S. M., El Haddad, I., Zardini, A. A., Clairotte, M., Astorga, C., Wolf, R., Slowik, J. G., Temime-Roussel, B., Marchand, N., Ježek, I., Drinovec, L., Mocnik, G., Möhler, O., Richter, R., Barmet, P., Bianchi, F., Baltensperger, U., and Prévôt, A. S. H.: Secondary organic aerosol formation from gasoline vehicle emissions in a new mobile environmental reaction chamber, Atmos. Chem. Phys., 13, 9141-9158, doi:10.5194/acp-13-91412013, 2013.

Presto, A. A., Huff Hartz, K. E., and Donahue, N. M.: Secondary Organic Aerosol Production from Terpene Ozonolysis. 1. Ef- fect of UV Radiation, Environ. Sci. Technol., 39, 7036-7045, doi:10.1021/es050174m, 2005.

Pretsch, E., Bühlmann, P., and Badertscher, M.: Structure Determination of Organic Compounds, Springer Berlin Heidelberg, Germany, 2009.

Renlund, A. M. and Trott, W. M.: ArF Laser-induced decomposition of simple energetic niolecules, Chem. Phys. Lett., 107, 555-560, doi:10.1016/S0009-2614(84)85155-6, 1984.

Roberts, J. M. and Fajer, R. W.: UV absorption cross sections of organic nitrates of potential atmospheric importance and estimation of atmospheric lifetimes, Environ. Sci. Technol., 23, 945951, 1989.

Romonosky, D. E., Laskin, A., Laskin, J., and Nizkorodov, S. A.: High-Resolution Mass Spectrometry and Molecular Characterization of Aqueous Photochemistry Products of Common Types of Secondary Organic Aerosols, J. Phys. Chem. A, 119, 2594 2606, doi:10.1021/jp509476r, 2015.

Romonosky, D. E., Ali, N. N., Saiduddin, M. N., Wu, M., Lee, H. J., Aiona, P. K., and Nizkorodov, S. A.: Effective absorption cross sections and photolysis rates of anthropogenic and biogenic secondary organic aerosols, Atmos. Environ., 130, 172179, doi:10.1016/j.atmosenv.2015.10.019, 2016.

Sander, S. P., Friedl, R. R., Barker, J. R., Golden, D. M., Kurylo, M. J., Wine, P. H., Abbatt, J. P. D., Burkholder, J. B., Kolb, C. E., Moortgat, G. K., Huie, R. E., and Orkin, V. L.: Chemical Kinetics and Photochemical Data for Use in Atmospheric Studies Evaluation Number 17, National Aeronautics and Space Administration and Jet Propulsion Laboratory, California Institute of Technology, Pasadena, CA, USA, 2011.

Saukko, E., Lambe, A. T., Massoli, P., Koop, T., Wright, J. P., Croasdale, D. R., Pedernera, D. A., Onasch, T. B., Laaksonen, A., Davidovits, P., Worsnop, D. R., and Virtanen, A.: Humiditydependent phase state of SOA particles from biogenic and anthropogenic precursors, Atmos. Chem. Phys., 12, 7517-7529, doi:10.5194/acp-12-7517-2012, 2012.

Schmidt, G. A., Kelley, M., Nazarenko, L., Ruedy, R., Russell, G. L., Aleinov, I., Bauer, M., Bauer, S. E., Bhat, M. K., Bleck, R., Canuto, V., Chen, Y., Cheng, Y., Clune, T. L., Del Genio, A., de Fainchtein, R., Faluvegi, G., Hansen, J. E., Healy, R. J., Kiang, N. Y., Koch, D., Lacis, A. A., LeGrande, A. N., Lerner, J., Lo, K. K., Matthews, E. E., Menon, S., Miller, R. L., Oinas, V., Oloso, A. O., Perlwitz, J. P., Puma, M. J., Putman, W. M., Rind, D., Romanou, A., Sato, M., Shindell, D. T., Sun, S., Syed, R. A., Tausnev, N., Tsigaridis, K., Unger, N., Voulgarakis, A., Yao, M.-S., and Zhang, J.: Configuration and assessment of the GISS ModelE2 contributions to the CMIP5 archive, J. Adv. Model. Earth Syst., 6, 141-184, doi:10.1002/2013MS000265, 2014

Seakins, P. W.: A brief review of the use of environmental chambers for gas phase studies of kinetics, chemical mechanisms and characterisation of field instruments, EPJ Web Conf., 9, 143-163, doi:10.1051/epjconf/201009012, 2010.

Sharpless, C. M. and Blough, N. V: The importance of charge-transfer interactions in determining chromophoric dissolved organic matter (CDOM) optical and photochemical properties, Environ. Sci. Process. Impacts, 16, 654-671, doi:10.1039/c3em00573a, 2014.

Smith, J. D., Kroll, J. H., Cappa, C. D., Che, D. L., Liu, C. L., Ahmed, M., Leone, S. R., Worsnop, D. R., and Wilson, K. R.: The heterogeneous reaction of hydroxyl radicals with sub- 
micron squalane particles: a model system for understanding the oxidative aging of ambient aerosols, Atmos. Chem. Phys., 9, 3209-3222, doi:10.5194/acp-9-3209-2009, 2009.

Strollo, C. M. and Ziemann, P. J.: Products and mechanism of secondary organic aerosol formation from the reaction of 3methylfuran with $\mathrm{OH}$ radicals in the presence of $\mathrm{NO}_{x}$, Atmos. Environ., 77, 534-543, doi:10.1016/j.atmosenv.2013.05.033, 2013.

Tkacik, D. S., Lambe, A. T., Jathar, S., Li, X., Presto, A. A., Zhao, Y., Blake, D., Meinardi, S., Jayne, J. T., Croteau, P. L., and Robinson, A. L.: Secondary Organic Aerosol Formation from in-Use Motor Vehicle Emissions Using a Potential Aerosol Mass Reactor, Environ. Sci. Technol., 48, 11235-11242, doi:10.1021/es502239v, 2014.

Tsang, W.: Chemical kinetic data base for combustion chemistry part V. Propene, J. Phys. Chem. Ref. data, 20, 221-274, doi:10.1063/1.555880, 1991.

Turro, N. J., Ramamurthy, V., and Scaiano, J. C.: Principles of Molecular Photochemistry: An Introduction, University Science Books, Sausalito, CA, USA, available at: http://www.uscibooks. com/turro2.htm (last access: November 2015), 2009.

Updyke, K. M., Nguyen, T. B., and Nizkorodov, S. A.: Formation of brown carbon via reactions of ammonia with secondary organic aerosols from biogenic and anthropogenic precursors, Atmos. Environ., 63, 22-31, doi:10.1016/j.atmosenv.2012.09.012, 2012.

Wang, B., Lambe, A. T., Massoli, P., Onasch, T. B., Davidovits, P., Worsnop, D. R., and Knopf, D. A.: The deposition ice nucleation and immersion freezing potential of amorphous secondary organic aerosol: Pathways for ice and mixed-phase cloud formation, J. Geophys. Res., 117, D16209, doi:10.1029/2012JD018063, 2012.
Wang, J., Doussin, J. F., Perrier, S., Perraudin, E., Katrib, Y., Pangui, E., and Picquet-Varrault, B.: Design of a new multi-phase experimental simulation chamber for atmospheric photosmog, aerosol and cloud chemistry research, Atmos. Meas. Tech., 4, 2465-2494, doi:10.5194/amt-4-2465-2011, 2011.

Warneke, C., Roberts, J. M., Veres, P., Gilman, J., Kuster, W. C., Burling, I., Yokelson, R., and de Gouw, J. A.: VOC identification and inter-comparison from laboratory biomass burning using PTR-MS and PIT-MS, Int. J. Mass Spectrom., 303, 6-14, doi:10.1016/j.ijms.2010.12.002, 2011.

Wong, J. P. S., Zhou, S., and Abbatt, J. P. D.: Changes in Secondary Organic Aerosol Composition and Mass due to Photolysis: Relative Humidity Dependence, J. Phys. Chem. A, 119, 4309-4316, doi:10.1021/jp506898c, 2015.

Zhang, X., Cappa, C. D., Jathar, S. H., McVay, R. C., Ensberg, J. J., Kleeman, M. J., and Seinfeld, J. H.: Influence of vapor wall loss in laboratory chambers on yields of secondary organic aerosol, P. Natl. Acad. Sci. USA, 111, 5802-5807, doi:10.1073/pnas.1404727111, 2014.

Zhang, Y., Xie, H., and Chen, G.: Factors Affecting the Efficiency of Carbon Monoxide Photoproduction in the St. Lawrence Estuarine System (Canada), Environ. Sci. Technol., 40, 7771-7777, doi:10.1021/es0615268, 2006.

Ziemann, P. and Atkinson, R.: Kinetics, products, and mechanisms of secondary organic aerosol formation, Chem. Soc. Rev., 41, 6582, doi:10.1039/c2cs35122f, 2012. 